\title{
Greenhouse Gas Emissions in a Dynamics- as-Usual Scenario of Economic and Energy Development
}

Keywan Riahi

R. Alexander Roehrl

International Institute for Applied Systems Analysis, Laxenburg, Austria

RR-00-16

August 2000

Reprinted from Technological Forecasting and Social Change 63, 175-205 (2000). 
Research Reports, which record research conducted at IIASA, are independently reviewed before publication. Views or opinions expressed herein do not necessarily represent those of the Institute, its National Member Organizations, or other organizations supporting the work.

Reprinted from Technological Forecasting and Social Change 63, 175-205 (2000).

Copyright (c) 2000, with permission from Elsevier Science Inc.

All rights reserved. No part of this publication may be reproduced or transmitted in any form or by any means, electronic or mechanical, including photocopy, recording, or any information storage or retrieval system, without permission in writing from the copyright holder. 


\title{
Greenhouse Gas Emissions in a Dynamics- as-Usual Scenario of Economic and Energy Development
}

\author{
KEYWAN RIAHI and R. ALEXANDER ROEHRL
}

\section{ABSTRACT}

This article describes two greenhouse gas (GHG) emission scenarios covering the period 1990-2100. The first of these, the B2 scenario, is a successful attempt to provide an internally consistent quantification-checked by the computer models Scenario Generator (SG), MESSAGE. MACRO. and MAGICC-of key variables describing a plausible but unremarkable "storyline" that complements the other storylines discussed in this special issue of Technological Forecasting and Social Change.

In the B2 scenario global carbon emissions from energy use and industrial sources rise from 6.5 gigatons of carbon (GtC) in 1990 to $14.2 \mathrm{GtC}$ in 2100 . Primary energy use climbs from 350 exajoules (EJ) to $1360 \mathrm{EJ}$. The global primary energy structure shifts away from gas and oil ( $28 \%$ in 2100 compared to $55 \%$ in 1990 ) and toward non-fossil energy sources ( $50 \%$ in 2100 compared in $18 \%$ in 1990$)$. The share of coal is $22 \%$ in 2100. only four percentage points lower than in 1990. Among regions there are significant variations in the primary energy structure. Synthetic liquid fuel production grows to $330 \mathrm{EJ}$ in 2100 . driven largely by assumptions about the long-term decline of oil and a continuation in current trends towards increasingly flexible. convenient. and cleaner forms of final energy:

On the global level sulfur emissions decline from 63 megatons of sulfur (MtS) in 1990 to $43 \mathrm{MtS}$ in 2100. Radiative forcing grows by approximately $1 \%$ per year from 1990 through 2100 . The "best guess" temperature change (assumed climate sensitivity $=2.5^{\circ} \mathrm{C}$ ) associated with this increase in radiative forcing is $2^{\circ} \mathrm{C}$ in 2100 .

The B2S550 scenario is a variation of the B2 scenario constrained to stabilize the atmospheric carbon concentration below 550 parts per million by volume (ppmv). Carbon emissions in the B2S550 scenario peak in 2040 at $10.7 \mathrm{GtC}$. before dropping to $5.5 \mathrm{GtC}$ by 2100 . Roughly $40 \%$ of the $8.7 \mathrm{GtC}$ difference in 2100 between the B2 scenario and the B2S550 scenario is due to fuel switching. primarily away from coal. $32 \%$ is from carbon scrubbing. $14 \%$ is due to price-induced energy demand reductions, and $12 \%$ is from hydrogen injection into the natural gas system. The B2S550 scenario"s radiative forcing in 2100 is $8 \%$ lower than that of the B2 scenario, and its best guess temperature change is $0.2^{\circ} \mathrm{C}$ lower. 2000 Elsevier Science Inc.

\section{Introduction}

The past decade has seen the development of many scenarios describing possible long-term patterns of future GHG emissions. The most extensive collection of such scenarios is that of Morita and Lee [1]. Their database includes over 400 scenarios,

KEYWAN RIAHI and R. ALEXANDER ROEHRL are affiliated with the International Institute for Applied Systems Analysis in Laxenburg. Austria.

Address correspondence to: Keywan Riahi, International Institute for Applied Systems Analysis (IIASA). Schlossplatz 1. A-2361 Laxenburg. Austria. E-mail: <riahi@iiasa.ac.at>.

Technological Forecasting and Social Change 63, 175-205 (2000)

(c) 2000 Elsevier Science Inc. All rights reserved. 
although not all are global or extend through 2100. Particularly well known scenario sets are the six IS92 scenarios developed by the IPCC in $1992[2,3]$ and the six IIASAWEC scenarios developed by the International Institute for Applied Systems Analysis (IIASA) and the World Energy Council (WEC) in 1998 [4].

The motivating question behind the B2 scenario that is the principal subject of this article was as follows. Is it possible to quantify the detailed features of a scenario such that:

1. They are all internally consistent according to the energy, economic, and emission models Scenario Generator (SG), MESSAGE, MACRO, and MAGICC;

2. They reflect a storyline (described in Section 2) that is plausible but unheroic in its assumptions while complementing the storylines described in other papers in this special issue (see Jiang et al. [5] for the A1 storyline. Sankovski et al. [6] for the A2 storyline, and de Vries et al. [7] for the B1 storyline): and

3. They incorporate advances in energy technologies that can be characterized as "dynamics-as-usual," i.e., long-term rates of technological change do not depart substantially from historical experience (see e.g. [8] and [9])?

The short answer is yes, it is possible to develop such a quantification, and the bulk of this article explains how it was done and the B2 scenario it produced. Because carbon emissions climb steadily in the $\mathrm{B} 2$ scenario, it is not a route to stabilizing the atmospheric carbon concentration before 2100 . The paper therefore introduces a variant, the B2S550 scenario, which includes a constraint to assure stabilization of the atmospheric carbon concentration at or below $550 \mathrm{ppmv}$ by 2100 . Otherwise the B2S550 scenario maintains all the features of the B2 storyline. In particular, cost reductions for individual technologies follow dynamics-as-usual trends and there is a greater emphasis on regional coherence and national self-sufficiency than on globalization.

The remainder of the article is organized as follows. Section 2 presents the B2 storyline. Section 3 summarizes the methods and models used to quantify the B2 scenario. Section 4 describes the data sources that have been used, and Section 5 discusses the main driving forces and inputs to the models, particularly population growth, economic growth and technological change.

Section 6 presents results for the B2 scenario in terms of the primary energy structure, energy intensity, and GHG emissions. Section 7 describes the B2S550 scenario and compares the climate impacts ${ }^{1}$ projected for both scenarios. Finally, Section 8 summarizes the findings and presents conclusions.

\section{B2 Storyline: Dynamics-as-Usual}

In the B2 storyline ${ }^{2}$ two features characterize government policies and business strategies. First is a trend toward local self-reliance and stronger communities. The shift toward local decision-making structures and institutions comes at the expense of international institutions, which decline in importance. In addition to technical solutions, priority issues are addressed through community-based, social solutions. The second

\footnotetext{
'As discussed in Wigley and Raper [10], the primary uncertainties in global mean temperature change estimates for any given emission scenario arise from uncertainties in the assumed climate sensitivity. The climate sensitivity defines the equilibrium response of the global mean surface air temperature to an instantaneous doubling of $\mathrm{CO}_{2}$, or $\mathrm{CO}_{2}$-equivalent, concentration. The IPCC best guess estimate of this parameter is $2.5^{\circ} \mathrm{C}$, with a range from $1.5^{\circ} \mathrm{C}$ to $4.5^{\circ} \mathrm{C}$ [11].

'The B2 storyline described here is built upon the original formulation by Stuart Gaffin of the Environmental Defense Fund (New York, NY, USA) and Nicolette Manson of Inform, Inc. (New York, NY, USA). (personal communication, 1998.)
} 
key characteristic is the continuing high priority given to environmental issues, at least at national and regional levels. The increasing attention given to national and regional green issues (and politicians) in the OECD over the last three decades keeps growing, and both transitioning and developing countries follow suit.

Continuing priority is also given to education and welfare, which leads to further reductions in mortality and, to a lesser extent, fertility. Population stabilizes at about 10 billion people by 2100 , consistent with both the United Nations and IIASA median projections $[12,13]$. Income per capita grows at an average of $2.1 \%$ per year through 2050 , reaching about US\$12,000. This compares to a historical average of $2.2 \%$ per year between 1950 and 1990 [14]. Between 2050 and 2100 average growth slows to about $1.3 \%$ per year. International income differences decrease considerably, from a ratio of 16-to-1 between North and South in 1990 to a ratio of 3-to-1 in 2100. Such reductions in international inequity are nonetheless less rapid than reduction in local inequities driven by stronger local initiatives and community support networks.

Strategies to address global environmental challenges in the B2 storyline are distinctly less successful than national and regional environmental response strategies, as governments have difficulty designing and implementing agreements that combine environmental protection with mutual economic benefits. In particular, the B2 storyline includes no explicit policies to limit carbon emissions. The absence of such policies in a storyline postulating generally high environmental awareness is explained partly by the focus in the B2 storyline on regional and national issues rather than global concerns and partly by the relative ineffectiveness of global institutions compared to regional and national institutions. ${ }^{3}$ At the regional level environmental policy cooperation in the B2 storyline leads to successful management of transboundary environmental problems such as acidification due to $\mathrm{SO}_{*}$, and the need to reduce the incidence of elevated tropospheric ozone levels through lower emissions of $\mathrm{NO}_{\mathrm{x}}$ and VOCs.

Global investment in energy RD\&D is modest, and mechanisms for the international diffusion of technology and know-how remain weak compared to the A1 and B1 storylines described elsewhere in this issue. Nevertheless, countries such as Japan, with rapid economic development and limited natural resources, place particular emphasis on technology development and bilateral co-operation. Technical change is therefore uneven across regions.

Land-use management becomes better integrated at the local level. Urban and transport infrastructures are a particular focus of community innovation, contributing to less dependence on automobiles and less urban sprawl. An emphasis on self-reliance for food contributes to a dietary shift toward local products and, in countries with high population densities, less meat consumption.

The availability of natural resources-another important driving force influencing the evolution of energy systems-differs from region to region. This is partly due to differences in natural endowments and partly because global trade and coordinating international institutions are not as well developed as in the A1 and B1 storylines. In regions relatively poor in fossil fuels, the need to use resources more efficiently spurs the development of less carbon-intensive technologies.

While the B2 storyline's assumptions assume that national and regional environmental awareness continues to expand both in the OECD and elsewhere, we should note

\footnotetext{
"Elsewhere in this issue de Vries et al. address the lack of carbon limitation policies in an environmentally aware world in additional detail. They give the topic additional attention because the B1 storyline they present describes a world with even higher environmental awareness than in the B2 storyline, and with higher priority on international issues and greater success in international cooperation.
} 
that the emphasis on environmental awareness does not necessarily lead to an accelerated decline in primary energy intensity (i.e., the amount of primary energy needed to produce a unit of GDP). First, different quantifications of the storyline may yield different results, a point emphasized in this section's final paragraph. Our quantification of the B2 storyline does not assume a dramatic departure in environmental policies, only that the OECD countries want to keep continuously improving their environmental record and the transitioning and developing countries want to catch up environmentally as they catch up economically. As we will see in Section 6, one outcome of this assumption of gradually tightening national and regional environmental policies in line with past trends is that future decreases in primary energy intensity also continue along past trends. (However, when we look at absolute outcomes 100 years hence, instead of at trends, the changes can be substantial. Section 6 shows that 100 years of incrementally tightening national and regional environmental policies add up to, in particular, much lower absolute sulfur emissions.) The second reason that environmental priorities in the B2 scenario need not lead to accelerated energy intensity reductions is that the turn away from globalization slows the extent to which international trade and competition motivate and disseminate efficiency improvements. Third, while efficiency improvements generally reduce pollution, the converse is not always true. Pollution reduction can also generate its own new energy demands.

Finally, before moving on to the models, data, and methods used to produce our quantification of the B2 storyline, it is important to emphasize that the storyline determines the energy system only loosely. Indeed there are many energy futures that could evolve from the B2 storyline. Its purpose is to provide a broad framework within which our particular quantification describes only one of many possible future energy system trajectories.

\section{Models}

The principal models and data sets used to translate the B2 storyline into quantitative scenario projections are shown in Figure 1. They are the Scenario Generator (SG), the bottom-up systems engineering model MESSAGE, the top-down macroeconomic model MACRO, the climate impact model MAGICC $[10,15,16]$ and several databases, most importantly the energy technology database CO2DB. We describe each in turn.

\subsection{SCENARIO GENERATOR}

The Scenario Generator $[4,17]$ is a simulation model to help formulate scenarios of economic and energy development for eleven world regions analyzed by MESSAGE. Its main objective is to allow fast scenario formulation and documentation of key scenario assumptions, and to provide common, consistent input data for MESSAGE and MACRO.

Within the SG there are, first, consistent sets of economic and energy data for the base year 1990, plus time series of such data for prior years. Second, the SG contains a set of regression equations estimated using the economic and energy data sets. These equations represent key relationships between economic and energy development, based on empirical data, that can be used selectively in formulating scenarios such as the B2 scenario described in this paper. To allow adjustments for different storylines and variants, all important variables are formulated so that a user can overwrite the values suggested by the equation of the SG.

Inputs to the SG are future population trajectories for eleven world regions used by MESSAGE plus key parameters determining regional per capital GDP growth. The 


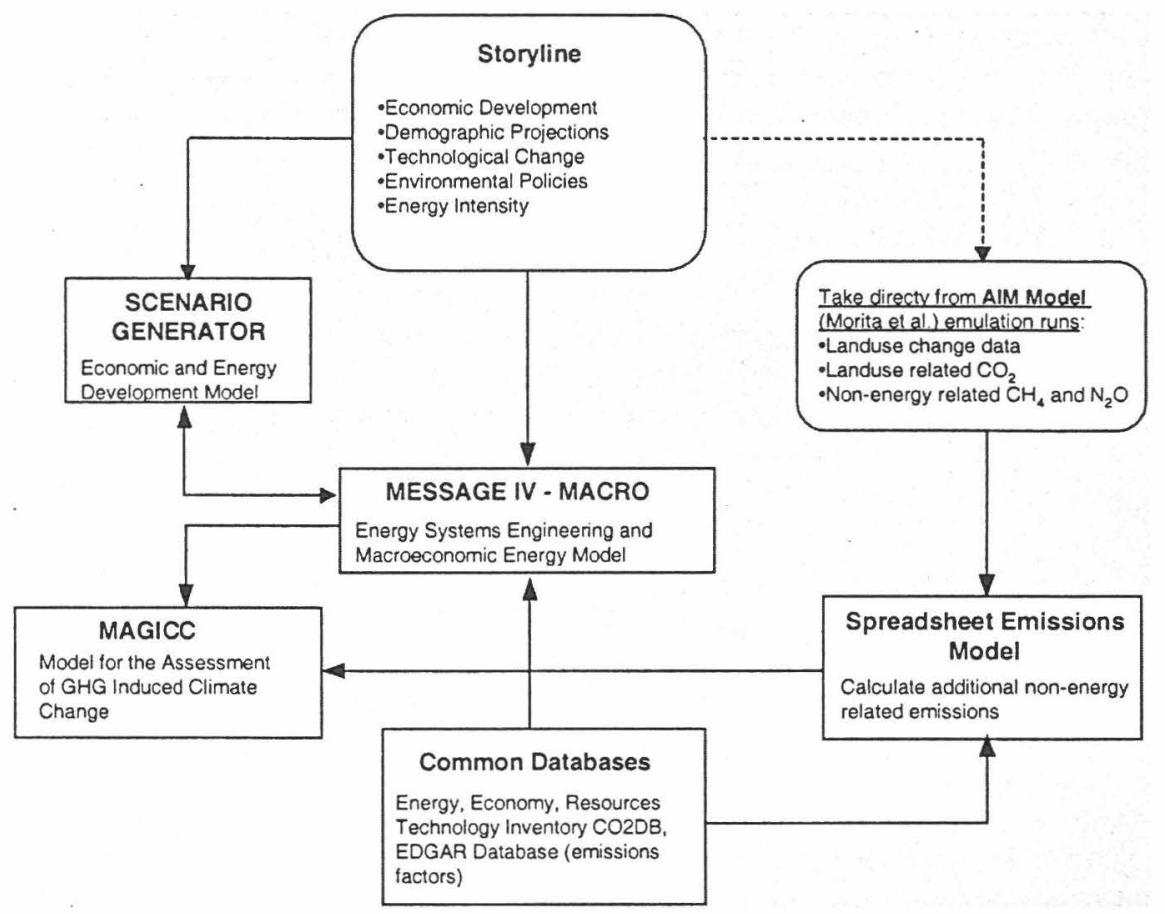

Fig. 1. The IIASA modeling framework used for the B2 and B2S550 scenarios, including the Scenario Generator, MESSAGE IV, MACRO, and associated databases. The climate impact model MAGICC $[1,12,13]$ was used in addition to calculate GHG concentrations and changes in radiative forcing, global temperature, and sea level rise.

SG first calculates growth rates of total GDP for each world region. Second, it calculates total final energy trajectories for each region by combining the population and per capita GDP growth trajectories with final energy intensity profiles based on the SG's set of empirically derived equations. The resulting final energy demands are then disaggregated, again based on combining regional per capita income growth with the SG's set of empirically derived equations, into the six demand sectors used by MESSAGE and listed below. In the list, "specific" energy demands are those that require electricity (or its substitutes such as, in the long term, hydrogen). "Non-specific" energy demands are mainly thermal requirements that can be fulfilled by any energy form.

- industrial specific

- industrial non-specific

- residential/commercial specific

- residential/commercial non-specific

- transportation

- non-commercial (e.g., fuelwood)

\subsection{SYSTEMS ENGINEERING MODEL MESSAGE}

MESSAGE (Model for Energy Supply Strategy Alternatives and their General Environmental Impact) is a systems engineering optimization model used for mediumto long-term energy system planning, energy policy analysis, and scenario development $[4,18]$. The model provides a framework for representing an energy system with all its 
interdependencies from resource extraction, imports and exports, conversion, transport, and distribution, to the provision of energy end-use services such as light, space conditioning, industrial production processes, and transportation. The model's current version, MESSAGE IV, provides information on the utilization of domestic resources, energy imports and exports and trade-related monetary flows, investment requirements, the types of production or conversion technologies selected (technology substitution), pollutant emissions, inter-fuel substitution processes, as well as temporal trajectories for primary, secondary, final, and useful energy.

The degree of technological detail in the representation of an energy system is flexible and depends on the geographical and temporal scope of the problem being analyzed. A typical model application is constructed by specifying performance characteristics of a set of technologies and defining a Reference Energy System (RES) that includes all the possible energy chains that the model can make use of. Section 5 describes the technology and resource cost assumptions for the RES used in the B2 scenario. In the course of a model run MESSAGE will then determine how much of the available technologies and resources are actually used to satisfy a particular enduse demand, subject to various constraints, while minimizing total discounted energy system costs.

\subsection{MACROECONOMIC MODEL MACRO}

MACRO is a top-down macroeconomic model [19]. Its objective function is the total discounted utility of a single representative producer-consumer. The maximization of this utility function determines a sequence of optimal savings, investment, and consumption decisions. In turn, savings and investment determine the capital stock. The capital stock, available labor, and energy inputs determine the total output of an economy according to a nested constant elasticity of substitution (CES) production function. Energy demand in two categories (electricity and non-electric energy) is determined within the model, consistent with the development of energy prices and the energy intensity of GDP.

The main determinants of energy demand are the reference GDP growth input into the model and the development of the overall energy intensity of GDP. Energy supply is represented by two quadratic cost functions, one for each of MACRO's two demand categories, and is determined so as to minimize costs. MACRO's outputs include internally consistent projections of world and regional realized GDP (i.e., taking into account the feedback that changing energy, and other, costs have on economic growth) including the disaggregation of total production into macroeconomic investment, overall consumption, and energy costs.

\subsection{CLIMATE CHANGE MODEL MAGICC}

To estimate aggregate climate impacts of the B2 and B2S550 scenarios we used Version 2.3 of the climate change model MAGICC (Model to Assess Greenhouse-gas Induced Climate Change) [1]. MAGICC includes a carbon cycle model that relates atmospheric inputs (emissions) and outputs (physical and chemical sink processes) to changes in the atmospheric carbon concentration. It uses carbon dioxide $\left(\mathrm{CO}_{2}\right)$, methane $\left(\mathrm{CH}_{4}\right)$, sulfur dioxide $\left(\mathrm{SO}_{2}\right)$, and nitrogen oxide $\left(\mathrm{NO}_{\mathrm{x}}\right)$ energy-related emissions from MESSAGE together with emission profiles for other greenhouse gases and non-energy related activities calculated as described in Section 5. The model estimates net carbon flows and atmospheric $\mathrm{CO}_{2}$ concentrations, changes in radiative forcing and temperature relative to 1990 , and sea level rise. 


\section{Data Sources}

This section identifies important data sources beyond the historical energy use and economic data incorporated in the SG. These include our sources for the B2 scenario's population trajectories, technology costs and improvement rates, and resource assumptions, plus information needed to calculate or incorporate directly relevant emissions not calculated by MESSAGE (e.g., emissions due to land-use changes and non-energyrelated emissions from the industrial sector).

The first exogenous inputs required by the SG are population trajectories for the eleven regions in MESSAGE. As the B2 storyline postulates no deviations from current population trends, we use the UN median population projections from 1998 [9]. These are described in more detail in Section 5.

The principal data source for initial technology costs is the energy technology database CO2DB developed at IIASA [20]. CO2DB currently includes more than 1600 technologies and associated information on their recent, current, and projected costs, efficiencies, and environmental characteristics. Distributions for initial costs for specific technologies can be extracted from CO2DB. These can then be processed (see, e.g., Strubegger and Reitgruber [21]) to adjust for non-independence among some data entries and for outliers. in order to estimate representative central values. Values for initial technology costs in the $\mathrm{B} 2$ scenario correspond to CO2DB's representative central values for most technologies. (We return to the exceptions in a moment.) Because CO2DB's information on cost improvement rates is quite limited, cost improvement rates in the $\mathrm{B} 2$ scenario are taken primarily from the IIASA-WEC study's Case B [6]. Case B is described as a "middle course" case with technological improvement assumptions that are "modest" but "pragmatic." This language matches well with the B2 storyline. There are some important exceptions where initial technology costs and subsequent cost reductions have been revised to reflect new data that were not included in CO2DB and Case B. These exceptions are principally low-sulfur technologies associated with the B2 storyline's emphasis on local and regional pollution control. We discuss the exceptions in Section 5.

Data on the availability of fossil energy resources are based on the work of Rogner [22] and are summarized in Table 1 [3]. The table groups the countries of the world into four aggregate regions that will be used throughout this article and are defined as follows.

- The OECD90 region groups together all countries belonging to the Organization for Economic Cooperation and Development as of 1990 and corresponds to Annex II countries under the UN Framework Convention on Climate Change (UNFCCC) [23].

- The REF region includes countries undergoing economic reform and groups together the East European countries and the newly independent states of the former Soviet Union. It includes Annex I countries outside Annex II as defined in the UNFCCC.

- The ASIA region includes all developing (non-Annex I) countries in Asia.

- The ALM region covers the rest of the world and includes all developing (nonAnnex I) countries in Africa, Latin America, and the Middle East.

Table 1 summarizes data on the available fossil resource base in terms of categories with which readers are likely to be most familiar [3]. Distinctions are made between reserves and resources, and between conventional and unconventional occurrences. For energy, the term "occurrence" covers all types and forms of hydrocarbon deposits in 
TABLE 1

World Hydrocarbon Resource Availability and Cumulative Use in the B2 Scenario from 1990 to 2100 in ZJ (1000 EJ)

\begin{tabular}{|c|c|c|c|c|c|c|}
\hline \multirow[b]{3}{*}{ Fuel } & \multicolumn{4}{|c|}{ World hydrocarbon reserves and resources $(\mathrm{ZJ})$} & \multirow[b]{3}{*}{ Total } & \multirow[b]{3}{*}{$\begin{array}{c}\text { B2 use: } \\
1990-2100\end{array}$} \\
\hline & \multirow{2}{*}{$\begin{array}{l}\text { Conventional: } \\
\text { Identified reserves } \\
\text { and resources }\end{array}$} & \multicolumn{3}{|c|}{ Unconventional } & & \\
\hline & & \multicolumn{2}{|r|}{$\begin{array}{l}\text { Identified } \\
\text { reserves }\end{array}$} & Resources & & \\
\hline Oil & 11.5 & & 7.1 & 1.5 & 20.1 & 19.4 \\
\hline Gas & 15.7 & & 6.9 & 12.8 & 35.4 & 26.9 \\
\hline \multirow[t]{3}{*}{ Coal } & 25.2 & & \multicolumn{2}{|c|}{100.3} & 125.5 & 12.6 \\
\hline & & \multicolumn{5}{|c|}{ Cumulative hydrocarbon use in the B2 scenario, 1990-2100 (ZJ) } \\
\hline & & Gas & & Oil & & Coal \\
\hline OECD & & 6.7 & & 3.0 & & 3.3 \\
\hline REF & & 7.7 & & 3.4 & & 1.5 \\
\hline ASIA & & 4.0 & & 1.7 & & 6.7 \\
\hline ALM & & 8.5 & & 11.3 & & 1.1 \\
\hline World & & 26.9 & & 19.4 & & 12.6 \\
\hline
\end{tabular}

Note that the categorization used here is consistent with the IPCC [5]. Therefore, the resource availability in the B2 Scenario is well within the IPCC estimates.

the Earth's crust, and "reserves" refers to those occurrences that are known and are recoverable with present technologies at prevailing market conditions. "Resources" are occurrences in addition to reserves that have less certain geological assurance or lack present economic feasibility, or both. Unconventional oil resources include oil shale, tar sands, and heavy crude, and unconventional natural gas resources include gas in Devonian shales, tight sand formations, geopressured aquifers. and coal seams. Table 1 does not include estimates of unconventional oil and gas resources that Rogner labels as "additional occurrences." The costs and uncertainties associated with these make any production with existing technology and at prevailing international market prices highly unlikely for the foreseeable future.

As input to the MESSAGE model the fossil resources in Table 1 are divided into more detailed cost categories as described in Section 5. MESSAGE then identifies how much of each resource category to use in successive time periods to most cost-effectively satisfy energy demand within the constraints set by technology costs, substitutability among energy forms, limits on how quickly new capacity can be expanded, and so on. To allow a comparison between the calculated use of fossil resources in the B2 scenario and the resource base shown in the table, the right column summarizes actual resource consumption calculated for the B2 scenario.

Nuclear resources are not a constraint in the B2 scenario. The use of uranium is well below the levels estimated in the IPCC's "Energy Primer" [24]. The potentials assumed for renewable resources are about twice the renewable potentials in the IIASAWEC study's Case B. The assumed increase was chosen to reflect the greater emphasis on regional and national environmental issues in the B2 scenario than in Case B.

Data related to relevant emissions not calculated by MESSAGE come from several sources. While MESSAGE directly calculates energy-related $\mathrm{CO}_{2}, \mathrm{CH}_{4}$, and $\mathrm{SO}_{\mathrm{x}}$ emissions. it does not calculate other energy-related emissions, non-energy-related emissions from industrial sources, or emissions due to land-use changes. Emissions in the first category (i.e.. other energy-related emissions) were calculated based on emission coeffi- 
TABLE 2

Regional and Global Economic and Population Growth Rates and Average Income (1990US\$) for the B2 Scenario

\begin{tabular}{|c|c|c|c|c|}
\hline Region & $1950-1990$ & $1990-2050$ & $2050-2100$ & $1990-2100$ \\
\hline \multicolumn{5}{|c|}{ Annual historical and scenario population growth rates } \\
\hline OECD90 & $1.1 \%$ & $0.21 \%$ & $-0.10 \%$ & $0.07 \%$ \\
\hline REF & $1.1 \%$ & $-0.03 \%$ & $-0.14 \%$ & $-0.08 \%$ \\
\hline ASIA & ASIA + ALM: & $0.86 \%$ & $0.11 \%$ & $0.52 \%$ \\
\hline ALM & $2.2 \%$ & $1.69 \%$ & $0.46 \%$ & $1.13 \%$ \\
\hline World & $1.8 \%$ & $0.96 \%$ & $0.21 \%$ & $0.62 \%$ \\
\hline \multicolumn{5}{|c|}{ Annual historical and scenario economic growth rates } \\
\hline OECD90 & $3.9 \%$ & $1.4 \%$ & $0.8 \%$ & $1.1 \%$ \\
\hline REF & $4.8 \%$ & $3.0 \%$ & $1.6 \%$ & $2.3 \%$ \\
\hline ASIA & $6.4 \%$ & $5.5 \%$ & $1.7 \%$ & $3.8 \%$ \\
\hline ALM & $4.0 \%$ & $4.1 \%$ & $2.1 \%$ & $3.2 \%$ \\
\hline World & $4.0 \%$ & $2.8 \%$ & $1.5 \%$ & $2.2 \%$ \\
\hline Region & 1990 & 2020 & 2050 & 2100 \\
\hline \multicolumn{5}{|c|}{ GDP per capita at market exchange rates, in US\$1.000 (1990) } \\
\hline OECD90 & 19.1 & 30.9 & 39.2 & 61.0 \\
\hline REF & 2.7 & 4.3 & 16.3 & 38.3 \\
\hline ASIA & 0.5 & 3.3 & 8.9 & 19.5 \\
\hline ALM & 1.6 & 2.4 & 6.9 & 16.1 \\
\hline World & 4.0 & 6.6 & 11.7 & 22.6 \\
\hline \multicolumn{5}{|c|}{ GDP per capita at purchasing power parity, in US\$1,000 (1990) } \\
\hline OECD90 & 16.4 & 26.8 & 34.4 & 54.3 \\
\hline REF & 6.2 & 7.9 & 17.7 & 42.7 \\
\hline ASIA & 1.9 & 5.6 & 10.5 & 20.2 \\
\hline ALM & 3.2 & 3.6 & 7.3 & 15.7 \\
\hline World & 4.9 & 7.8 & 12.2 & 22.3 \\
\hline
\end{tabular}

Note: Growth rate data from 1950 to 1990 and scenario projections from 1990 to 2100 (\%/year).

cients in the EDGAR database [25]. As described in Section 5 these emission coefficients were directly applied to the evolving relevant activity levels calculated by MESSAGE for the B2 scenario. Similarly, coefficients from the EDGAR database for non-energyrelated emissions from the industrial, residential/commercial, and transportation sectors were applied to the B2 activity levels in these sectors as calculated by MESSAGE.

To include emissions arising from land-use changes we first used directly the landuse emissions of $\mathrm{CO}_{2}, \mathrm{CH}_{4}$, and $\mathrm{N}_{2} \mathrm{O}$ calculated by Morita et al. in their quantification of the B2 storyline using the AIM model [26]. To estimate emission levels for other GHGs we then combined the activity levels associated with different land uses in Morita et al.'s B2 quantification with, again, emission coefficients from the EDGAR database.

\section{Driving Forces}

The UN median 1998 population projection [12] that is used for the B2 scenario describes a continuation of historical trends, including recent faster-than-expected fertility declines, toward a completion of the demographic transition within the next century. Global population increases to about 9.4 billion people by 2050 and 10.4 billion by 2100. Although, in the long term, global fertility level gradually approach replacement levels, the path and pace of fertility change vary greatly among the regions. For the four aggregate regions for which we report results, the top part of Table 2 shows that population growth is consistently highest in the ALM region, i.e., the developing coun- 
TABLE 3

Levelized Oil and Gas Costs by Category and Region

\begin{tabular}{|c|c|c|c|c|c|c|}
\hline & \multicolumn{6}{|c|}{ Crude oil extraction costs (levelized) by category, in US\$(1990)/boe } \\
\hline & Oil I & Oil II & & Oil III & Oil IV & Oil V \\
\hline OECD 90 & 12.6 & 18.1 & & 21.6 & 29.6 & 31.7 \\
\hline REF & 8.9 & 12.5 & & 16.3 & 24.6 & 27.8 \\
\hline ASIA & 4.3 & 9.8 & & 15.2 & 20.2 & 26.9 \\
\hline \multirow[t]{3}{*}{ ALM } & 4.3 & 9.8 & & 15.2 & 20.2 & 26.9 \\
\hline & \multicolumn{6}{|c|}{ Natural gas extraction costs (levilized) by category, in US\$ $(1990) /$ boe } \\
\hline & Gas I & Gas II & Gas III & Gas IV & Gas V & Gas VI \\
\hline OECD 90 & 10.5 & 15.0 & 20.5 & 25.3 & 27.8 & 34.8 \\
\hline REF & 6.6 & 10.2 & 17.5 & 20.2 & 25.3 & 32.4 \\
\hline ASIA & 4.2 & 9.6 & 15.1 & 19.9 & 25.0 & 30.1 \\
\hline ALM & 4.2 & 9.6 & 15.1 & 19.9 & 25.0 & 30.1 \\
\hline
\end{tabular}

tries in Africa, Latin America, and the Middle East. It is significantly lower in the ASIA region and, in the OECD90 region, averages negative values between 2050 and 2100 . For the REF region, average growth is negative both between 1990 and 2050 and from 2050 to 2100 . The global growth rate drops from a historical average of $1.8 \%$ between 1950 and 1990 to $0.96 \%$ from 1990 to 2050 , and $0.21 \%$ from 2050 to 2100 .

The second part of Table 2 summarizes regional economic growth rates chosen to be consistent with three factors: (1) historical relations within the SG reflecting conditional economic convergence ${ }^{4}$ across countries; (2) population growth as in the top part of Table 2; and (3) resulting global economic growth that approximates the median in Morita and Lee's database [1]. The growth patterns summarized in the table assume that all countries and regions eventually manage to take off successfully into a period of industrialization and accelerating economic development. In particular they reflect historical correlations between per capita GDP growth and decreasing fertility and mortality. They also reflect the pattern of faster growth in low-income countries than in high-income countries, leading to a conditional convergence of per capita income over the very long term. Where per capita growth is stagnating and there are no current signs of an economic take-off, as in Africa, peak economic growth is assumed to correspond to the period of the maximum decline in population growth rates.

Following Rogner's categorization of fossil energy resources [22], the resources summarized in Table 1 are divided into more detailed categories characterized by increasing extraction costs. Table 3 shows the average levelized oil and gas extraction costs for different categories for each of the four aggregate regions defined earlier. These costs remain constant throughout the MESSAGE calculations although the costs of the technologies that convert or consume these resources generally decrease over time. Summary definitions of the categories in Table 3 are as follows. Category I corresponds to identified reserves. Category II represents occurrences with a reasonable geological probability of discovery, such as conventional oil resources, and Category III corresponds to low probability estimates for discovering undiscovered conventional

\footnotetext{
${ }^{4}$ Conditional convergence recognizes persistent differences among countries, for example the difference between the United States' high-energy intensity development path and the lower-energy intensity development path of Japan. Under conditional convergence, developing countries do not all follow the development path of any one developed country or group of countries. Each follows whichever path, in its earlier stages, most closely corresponds to its current situation.
} 
oil and gas. Category IV reflects the potential for enhanced recovery. Category V contains identified reserves of unconventional oil and gas. Categories VI and higher cover additional occurrences that are increasingly uncertain or uneconomic given foreseeable technologies and market conditions. In the $\mathrm{B} 2$ and the $\mathrm{B} 2 \mathrm{~S} 550$ scenario the most expensive category of oil that is used is Category V. For gas it is Category VI.

Assumptions on the availability of uranium and renewable resource potentials are as described in Section 4. However, neither in the case of nuclear power nor in the case of renewable energy does resource availability prove an important constraint in the B2 scenario. More important are the patterns of technology improvements discussed next.

Initial costs for most technologies in the $\mathrm{B} 2$ scenario equaled the representative central values for CO2DB's cost distributions as discussed in Section 4. Cost improvement rates for most technologies were taken from the IIASA-WEC study's middlecourse Case B [4]. However, because the B2 storyline places greater emphasis on local and regional pollution control than does the IIASA-WEC Case B. parameters for particularly non-sulfur-emitting technologies were revised to reflect more recent and more promising performance projections. These non-sulfur-emitting technologies include in particular wind and solar photovoltaics, but also gas combined cycle, integrated gasification combined cycle (IGCC), solar thermal power plants, and advanced nuclear power plants. For conventional coal technologies, on the other hand, future extraction and conversion costs are less optimistic than in the IIASA-WEC Case B. In regions with large shares of deep mined coal and high population densities coal costs even increase, although they are assumed to remain relatively low in regions with abundant surface coal reserves such as North America and Australia. Figure 2 shows cost assumptions for the most important electricity generation technologies.

To calculate those GHG emissions not calculated by MESSAGE or AIM we applied emission coefficients derived from the EDGAR database to the evolving relevant activity levels calculated by MESSAGE. For example, emissions from cement production were calculated by first linking industrial thermal energy use (a proxy for heavy industry) from the MESSAGE model output to the base year activity data on cement production. and then applying the constant emission coefficient derived from the EDGAR database. The left sides of Tables 4 and 5 summarize the MESSAGE activity variables that were used in this way to calculate $\mathrm{N}_{2} \mathrm{O}$, halocarbon, $\mathrm{NO}_{*}$, and VOC emissions. Sulfur emissions from industrial sources for the OECD90 region were similarly calculated by linking base year emission coefficients to industrial thermal energy use. For the developing countries we assume that industrialization leads to initially increasing emission coefficients that, in later stages of development, then converge toward OECD90 values. The aggregated emission coefficient for developing countries grows from $1.2 \mathrm{kgS} / \mathrm{MJ}$ in 1990 to some $3.4 \mathrm{kgS} / \mathrm{MJ}$ by 2050 , and then decreases to about $3 \mathrm{kgS} / \mathrm{MJ}$ by 2100 .

$\mathrm{CO}_{2}, \mathrm{~N}_{2} \mathrm{O}$, and $\mathrm{CH}_{4}$ emissions from land-use changes, which are not calculated by MESSAGE, were largely taken directly from Morita et al.'s quantification of the B2

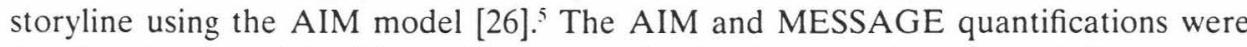
developed in parallel with regular communication between the two modeling groups to assure consistency. We assume that $\mathrm{NO}_{x} . \mathrm{CO}$, and $\mathrm{VOC}$ emissions from deforestation in developing countries decline roughly in line with the declining use of non-commercial biomass, although we recognize that non-commercial biomass is not a driver of deforesta-

'The AIM modeling group includes T. Morita, J. Kejun, and T. Masui, National Institute of Environmental Studies. Japan. 


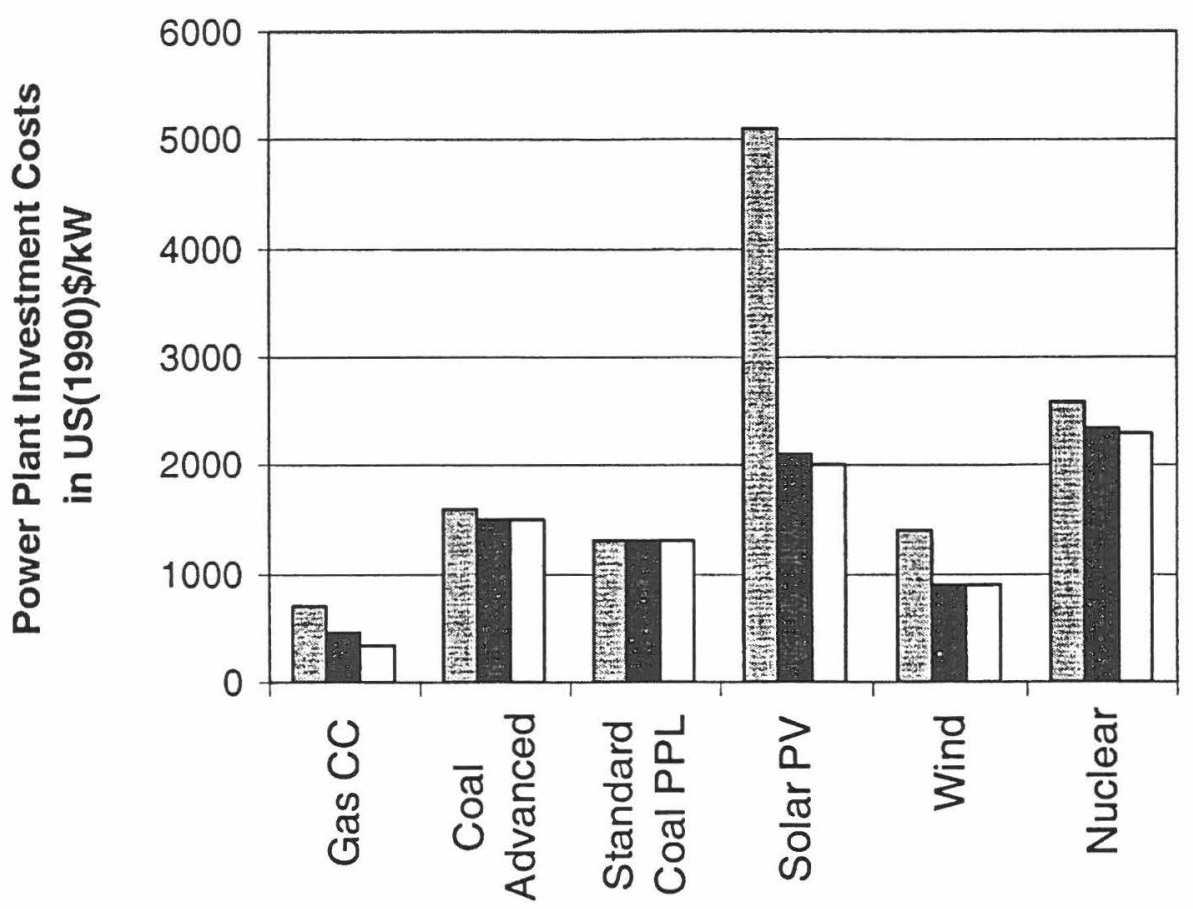

Fig. 2. Investment costs for the most important technologies in the electricity sector (gas combined cycle, coal advanced technology, standard coal power plant [with DENOX], solar photovoltaic, wind, and advanced reactors). Years: 1990 (shaded bars), 2050 (solid bars), and 2100 (open bars).

tion to the extent implicit in such an assumption. Of the indicators available from MESSAGE, however, it is the one most straightforwardly connected to deforestation. For emissions with particularly high uncertainties (e.g., $\mathrm{NO}_{x}$ from savanna burning) we assumed constant values. Sulfur emissions from non-energy related biomass burning were calculated by linking land-use change data for forests calculated by the AIM modeling group, with base year emission coefficients from the EDGAR database. Sulfur emissions from international shipping (bunker fuels) were assumed to remain constant at the present level of $3 \mathrm{MtS}$ per year.

\section{Results}

\subsection{ECONOMIC GROWTH}

Gross World Product (GWP) grows in the B2 scenario from US\$20 trillion to US $\$ 235$ trillion (1990) in $2100 .{ }^{6}$ This approximates the median of the scenarios in Morita and Lee's database [1] and corresponds to a long-term average growth rate of $2.2 \%$ from 1990 to 2100. Most of this growth takes place in today's developing countries, but over the long term economic growth rates in these regions also decline as labor productivity levels approach those of the leading countries. As a result, average GWP per capita in the developing countries grows from US $\$ 850$ today to US $\$ 18,000$ in 2100 , about the same level as the OECD in 1990. For industrialized countries, per capita GWP increases

\footnotetext{
${ }^{6}$ When not explicitly mentioned in the text, GWP and GDP are reported at market exchange rates.
} 
TABLE 4

Anthropogenic $\mathrm{N}_{2} \mathrm{O}$ and NO, Emissions for the B2 Scenario

\begin{tabular}{|c|c|c|c|c|c|c|}
\hline & \multirow{2}{*}{$\begin{array}{c}\text { MESSAGE activity } \\
\text { variable }^{\mathrm{a}}\end{array}$} & \multicolumn{5}{|c|}{ B2-Anthropogenic emissions } \\
\hline & & Unit & 1990 & 2020 & 2050 & 2100 \\
\hline $\mathrm{N}: \mathrm{O}$ emissions & & $\mathrm{MtN}$ & 6.56 & 5.69 & 5.92 & 6.57 \\
\hline Energy-related & & & 0.22 & 0.31 & 0.38 & 0.44 \\
\hline Power generation & Fossil electricity generation & & 0.05 & 0.10 & 0.14 & 0.25 \\
\hline Transportation & $\mathrm{FE}^{\mathrm{b}}-$ fossil transport & & 0.06 & 0.09 & 0.12 & 0.09 \\
\hline Industry & $\mathrm{FE}$ - Industry thermal ${ }^{\mathrm{C}}$ & & 0.03 & 0.05 & 0.06 & 0.05 \\
\hline Other sectors ${ }^{\downarrow}$ & $\mathrm{RC}^{\mathrm{c}}$ - fossil non-electricity & & 0.03 & 0.04 & 0.05 & 0.04 \\
\hline Biofuels (residential sector) & NC biomass use & & 0.05 & 0.03 & 0.01 & 0.01 \\
\hline Non-energy-related & & & 6.34 & 5.38 & 5.54 & 6.13 \\
\hline Nitric and adipic acid & - & & 0.73 & 0.54 & 0.51 & 0.64 \\
\hline Manure management & - & & 4.32 & 4.54 & 4.78 & 5.21 \\
\hline Deforestation & - & & 1.06 & 0.06 & 0.00 & 0.00 \\
\hline Biomass and agricultural & & & & & & \\
\hline waste burning & - & & 0.23 & 0.24 & 0.26 & 0.28 \\
\hline NO, emissions & & $\mathrm{MtN}$ & 31.0 & 45.5 & 57.3 & 64.1 \\
\hline Energy-related & & & 23.4 & 37.6 & 49.2 & 56.5 \\
\hline Power generation & Fossil electricity generation & & 6.3 & 12.1 & 17.8 & 32.2 \\
\hline Transportation & $F E^{h}-$ fossil transport & & 10.7 & 17.2 & 22.1 & 16.8 \\
\hline Industry & $\mathrm{FE}^{h}$ - Industry thermal ${ }^{c}$ & & 3.3 & 5.0 & 6.2 & 5.2 \\
\hline Other sectors & $\mathrm{RC}^{-}$- fossil non-electricity & & 1.6 & 2.3 & 2.8 & 2.0 \\
\hline Biofuels (residential sector) & NC biomass use' & & 1.5 & 1.0 & 0.4 & 0.3 \\
\hline Non-energy-related & & & 7.6 & 7.9 & 8.1 & 7.6 \\
\hline Industrial processes & $\mathrm{FE}^{\mathrm{r}}$ - Industry thermal ${ }^{\mathrm{c}}$ & & 1.5 & 2.2 & 2.7 & 2.3 \\
\hline Deforestation ${ }^{\mathrm{h}}$ & NC biomass use ${ }^{\prime}$ & & 1.1 & 0.7 & 0.3 & 0.2 \\
\hline Savanna burning ${ }^{i}$ & - & & 2.9 & 2.9 & 2.9 & 2.9 \\
\hline Agricultural waste burning & - & & 2.2 & 2.2 & 2.2 & 2.2 \\
\hline
\end{tabular}

"MESSAGE activity variables were linked to the base year emission activities from the EDGAR database.

${ }^{\mathrm{h}} \mathrm{FE}=$ final energy:

"A proxy for heavy industry.

"The category "other sectors" includes all energy-related emissions that are not related to the industry. transportation, or power generation sectors (mainly fossil fuels for themal (non-electric) uses in the residential/ commercial sector).

$\cdot \mathrm{RC}=$ residential/commercial sector.

' $\mathrm{NC}=$ non-commercial biomass use.

"Non-energy related emissions for $\mathrm{N}_{2} \mathrm{O}$ were taken from the AIM B2 run.

${ }^{h}$ Decline in line with non-commercial use of biomass.

' $N O$, emissions from savanna burning. agricultural waste burning. and uncontrolled waste burning were assumed to be constant.

to US\$54,000 in 2100 . These increases reduce the income ratio between North and South from 16-to-1 in 1990 to 3-to-1 in the year 2100.

\subsection{ENERGY INTENSITY AND FINAL ENERGY DEMAND}

The amount of final energy demand per unit of GDP, i.e., final energy intensity, decreases in the B2 scenario as inefficient technologies are retired in favor of more efficient ones and as economic development shifts the structure of the energy system toward less energy-intensive activities. The decrease is greatest for developing countries in the first half of the next century where high economic growth results in a rapid turnover of capital stock and consequent rapid change in the structure of the energy system. The average rate by which the final energy intensity in the ASIA region declines, for example, is $3.2 \%$ from 1990 to 2050 . Once the transition to a post-industrial economic 
TABLE 5

Anthropogenic CO, VOCs, and Halocarbon Emissions for the B2 Scenario

\begin{tabular}{|c|c|c|c|c|c|c|}
\hline & \multirow{2}{*}{$\begin{array}{c}\text { MESSAGE activity } \\
\text { variable: }\end{array}$} & \multicolumn{5}{|c|}{ B2-Anthropogenic emissions } \\
\hline & & Unit & 1990 & 2020 & 2050 & 2100 \\
\hline $\mathrm{CO}$ emissions & & $\mathrm{MtC}$ & 417 & 443 & 581 & 875 \\
\hline Energy-related & & & 190 & 270 & 409 & 710 \\
\hline Fossil fuels & Fossil transport & & 112 & 181 & 232 & 177 \\
\hline Biofuels & $\mathrm{FE}^{\mathrm{c}}-$ Biomass use & & 78 & 89 & 177 & 533 \\
\hline Non-energy-related & & & 227 & 173 & 172 & 165 \\
\hline Industrial processes & $\mathrm{FE}^{\mathrm{c}}$ - Industry thermal ${ }^{\mathrm{d}}$ & & 15 & 22 & 28 & 24 \\
\hline Deforestation & NC biomass use' & & 48 & 30 & 13 & 9 \\
\hline Savanna burning: & - & & 76 & 76 & 76 & 76 \\
\hline Agricultural waste burning & - & & 89 & 89 & 89 & 89 \\
\hline VOC emissions & & $\mathrm{Tg}$ & 178 & 221 & 259 & 213 \\
\hline Energy-related & & & 100 & 136 & 163 & 127 \\
\hline Fossil fuels & Fossil transport & & 42 & 67 & 86 & 66 \\
\hline Oil production & Oil extraction & & 22 & 34 & 36 & 8 \\
\hline Gas production & Gas extraction & & 3 & 5 & 11 & 12 \\
\hline Gas transmission & Piped gas exports & & 2 & 10 & 22 & 35 \\
\hline Biofuels & NC biomass use & & 31 & 20 & 9 & 6 \\
\hline Non-energy-related & & & 78 & 85 & 96 & 86 \\
\hline Industry & $\mathrm{FE}^{\mathrm{c}}$ - Industry thermal ${ }^{\lrcorner}$ & & 33 & 50 & 62 & 53 \\
\hline Deforestation & NC biomass use & & 8 & 5 & 2 & 1 \\
\hline Other & - & & 37 & 37 & 37 & 37 \\
\hline Halocarbons $^{h}$ & & $\mathrm{MtC}$ eq. & 1.778 & 510 & 759 & 1.102 \\
\hline (H)CFCs & - & & 1.650 & 126 & 4 & 0 \\
\hline HFCs & - & & 33 & 212 & 441 & 707 \\
\hline PFCs & - & & 57 & 101 & 186 & 229 \\
\hline SF6 & - & & 38 & 71 & 128 & 166 \\
\hline
\end{tabular}

"MESSAGE activity variables were linked to the base year emission activities from the EDGAR database.

"Mainly emissions from the transport sector.

' $\mathrm{FE}=$ final energy.

A A proxy for heavy industry.

"Decline in line with non-commercial use of biomass.

$\mathrm{NC}=$ non-commercial biomass use.

: CO emissions from savanna burning. agricultural waste burning. and uncontrolled waste burning were assumed to be constant.

${ }^{\text {h}}$ Halocarbon emissions for the B2 scenario were calculated by Joergen Fenhann (see Fenhann's article in this special issue).

structure is complete the rate of decline slows (see Figure 3). Between 2050 and 2100 it averages to $0.7 \%$. The patterns in Figure 3 reflect the regional, rather than global, emphasis in the underlying B2 storyline, in that there is only relative and not absolute convergence in energy intensity levels across regions. Different regions follow different development paths and there are some persistent differences in energy intensities even at similar levels of per capita income. However, the aggregate global rate at which final energy intensity declines is about one percent per year through 2100 .

Figure 4 shows the continuing trend in the B2 scenario toward more flexible, more convenient. and cleaner forms of final energy. Given a choice, people generally prefer to heat their houses with gas, for example, rather than coal, even when coal is cheaper, and as incomes grow, people are increasingly willing to pay for more conventional and higher quality forms of energy. By 2100 the total world final energy share of electricity, hydrogen. and district heat has increased to $56 \%$, up from $15 \%$ in 1990 . 


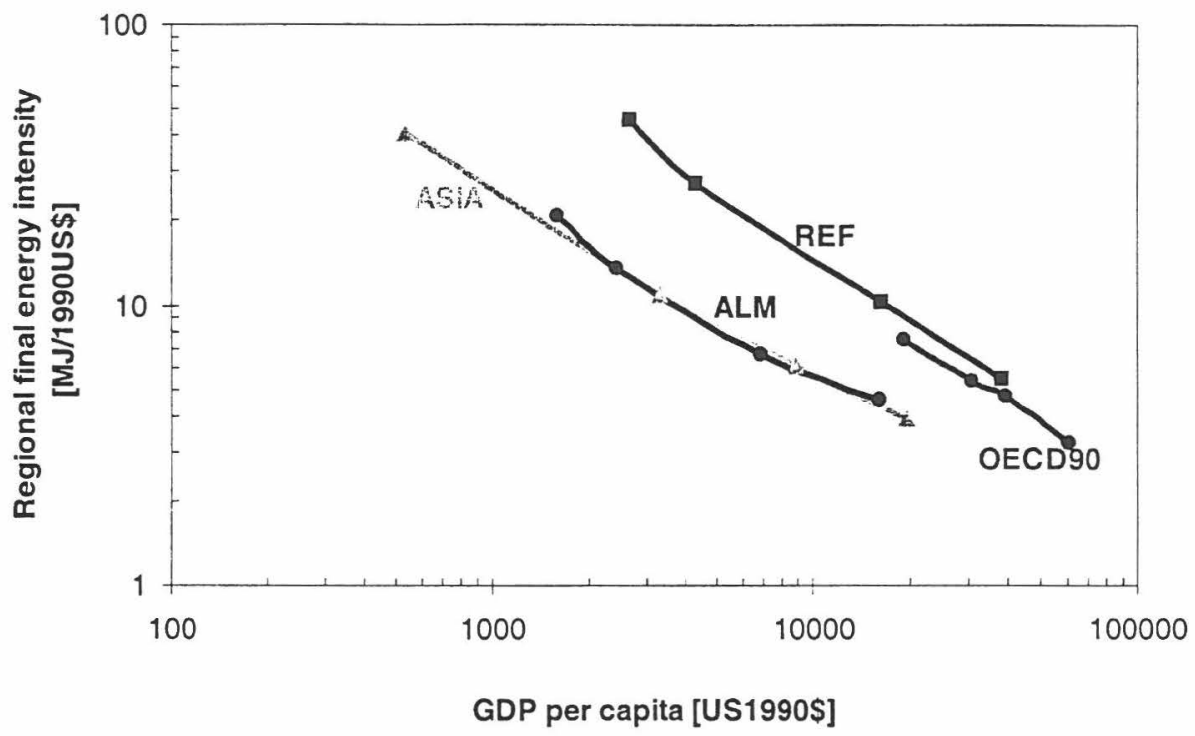

Fig. 3. Relationship between final energy intensity and per capita income in the B2 scenario. The markers correspond to $1990,2020,2050$, and 2100.

\subsection{ENERGY EFFICIENCY}

The efficiency of final energy use improves for two reasons in the B2 scenario. First, the mix of final energy carriers shifts toward higher quality fuels such as electricity. Second, the aggregate efficiency of end-use technologies such as light bulbs, furnaces, and automobiles improves due to technological change. As the final energy mix shifts toward higher quality fuels, however, primary-to-final energy conversion efficiency declines. Transforming coal into electricity before delivering it to the end user is quite

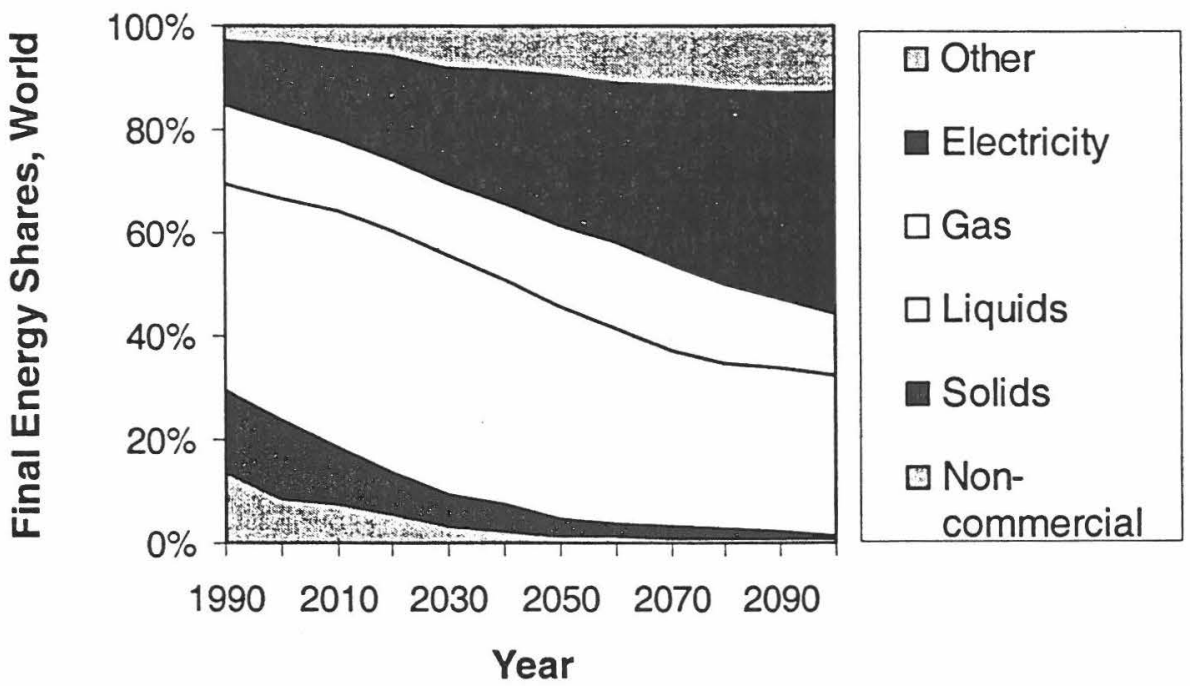

Fig. 4. World final energy shares in the B2 scenario. The category "Other" includes hydrogen, district heat, and direct heat from solar home collectors. 


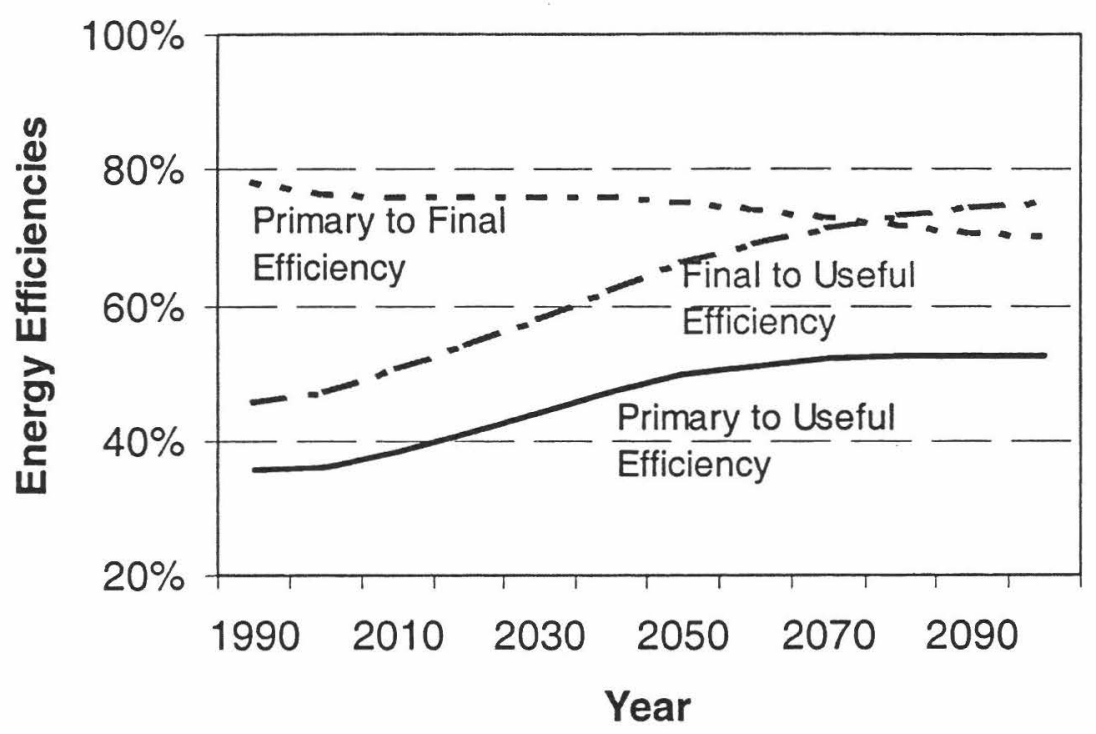

Fig. 5. World energy efficiencies. Final energy includes non-commercial biomass with an efficiency of $12 \%$. Primary energy was calculated by using the direct equivalent method for all non-thermal uses of renewables and nuclear.

simply a more extensive conversion than simply preparing it for use in a coal furnace. Thus the aggregate primary-to-final energy conversion efficiency in the B2 scenario drops from $78 \%$ in 1990 to $70 \%$ in 2100 . As shown in Figure 5, however, the increases in final energy efficiency outpace the decreases in primary-to-final energy efficiency, and the overall energy system efficiency, from primary to useful energy, ${ }^{7}$ increases substantially, from $36 \%$ in 1990 to $53 \%$ in 2100 .

\subsection{PRIMARY ENERGY}

Global primary energy needs in the B2 scenario increase by a factor of 2.5 from $350 \mathrm{EJ}$ in 1990 to $870 \mathrm{EJ}$ in 2050, and by almost a factor of four to $1360 \mathrm{EJ}$ in 2100. Most of this increase takes place in today's developing regions, and around 2020 the developing regions overtake the industrialized countries in terms of total primary energy use. Much of the increase in developing regions, however, is due to population growth. Thus per capita energy use never matches that in the industrialized countries. By 2100 per capita energy use in today's developing regions is just approaching what it was in the industrialized countries in 1990.

Figure 6 illustrates the long-term historical development of the world primary energy structure [4]. Also shown are the projected primary energy structure in the B2 scenario and, for comparison, in the IS92a scenario. (The third scenario shown in the figure, B2S550, is discussed in detail in Section 7). Each corner of the triangle corresponds to a hypothetical situation in which all primary energy is supplied by a single category of resources: oil and gas on the top, coal on the left, and non-fossil sources (renewables and nuclear) on the right. In 1990, the primary energy shares were $55 \%$ for oil and gas, $26 \%$ for coal, and $18 \%$ for non-fossil sources. Historically, the primary energy structure

${ }^{7}$ Useful energy is defined as the energy which is actually consumed by the end-user. e.g., radiation from light bulbs, heat from boilers or heat pumps, or kinetic energy from cars. Thus technologies at the useful energy level (light bulbs. automobiles, boilers, etc.) have final energy as an input and useful energy as an output. 


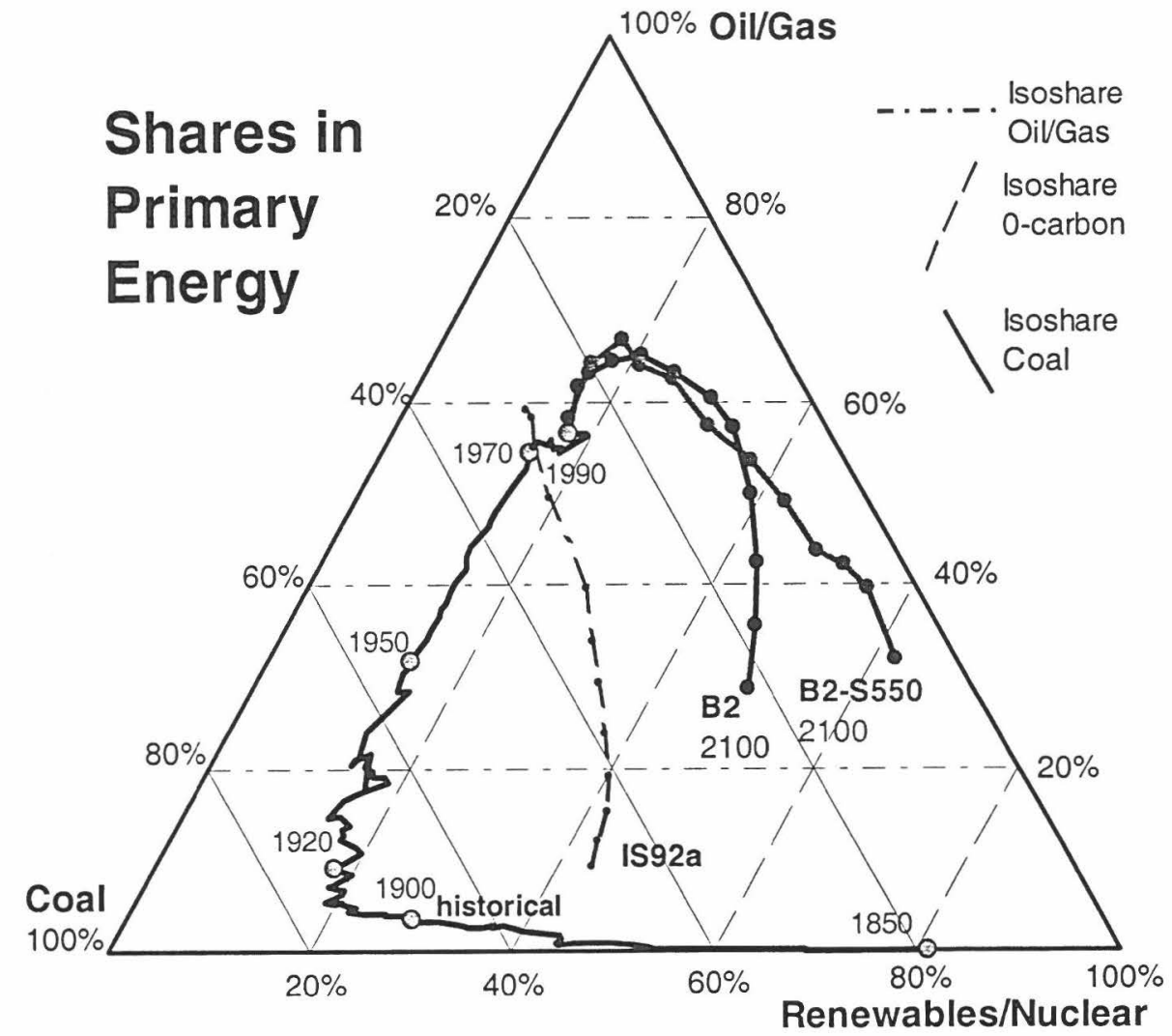

Fig. 6. Global shares, in percent, in primary energy use for coal, oil and gas, and non-fossil energy, illustrated with an "energy triangle." Historical data from 1850 to 1990 are taken from [6]. Also shown are trajectories from 1990 to 2100 for the B2, IS92, and B2S550 scenarios. Bullets on the 1990 to 2100 trajectories represent $\mathbf{1 0}$-year time steps. For further explanation of the figure, see the text.

has evolved "clockwise." That is, between 1850 and 1920 traditional renewables were replaced by coal, which reached its maximum share around 1920. Between 1920 and 1970 coal was replaced progressively by oil and gas. Since then changes in the primary energy mix have been comparatively modest.

Both the B2 scenario and the IS92a scenario continue the historical clockwise pattern, although the IS92a scenario makes a much tighter turn away from oil and gas and toward coal. In the B2 scenario the oil and gas share and the non-fossil share increase gradually during the first half of the next century. The non-fossil share continues to increase (from $15 \%$ in 1990 to $39 \%$ by 2100 ), but limited oil resources in particular lead to a decreasing oil and gas share and, eventually, a surge in coal. Coal production is essentially flat until about 2060 (see Figure 7), resulting in its declining share shown in Figure 6. After 2060, however, coal use expands, driven mainly by the demand for synthetic fuels. By 2100 , the primary energy shares are about $50 \%$ for non-fossil sources, $22 \%$ for coal, and $28 \%$ for oil and gas. The IS 92 a scenario's tighter turn away from oil and gas and toward coal is due to more limited resource availability than in the B2 scenario and slower assumed technological progress. The result is a more carbonintensive economy in IS92a with a coal share of $47 \%$ in 2100 . 


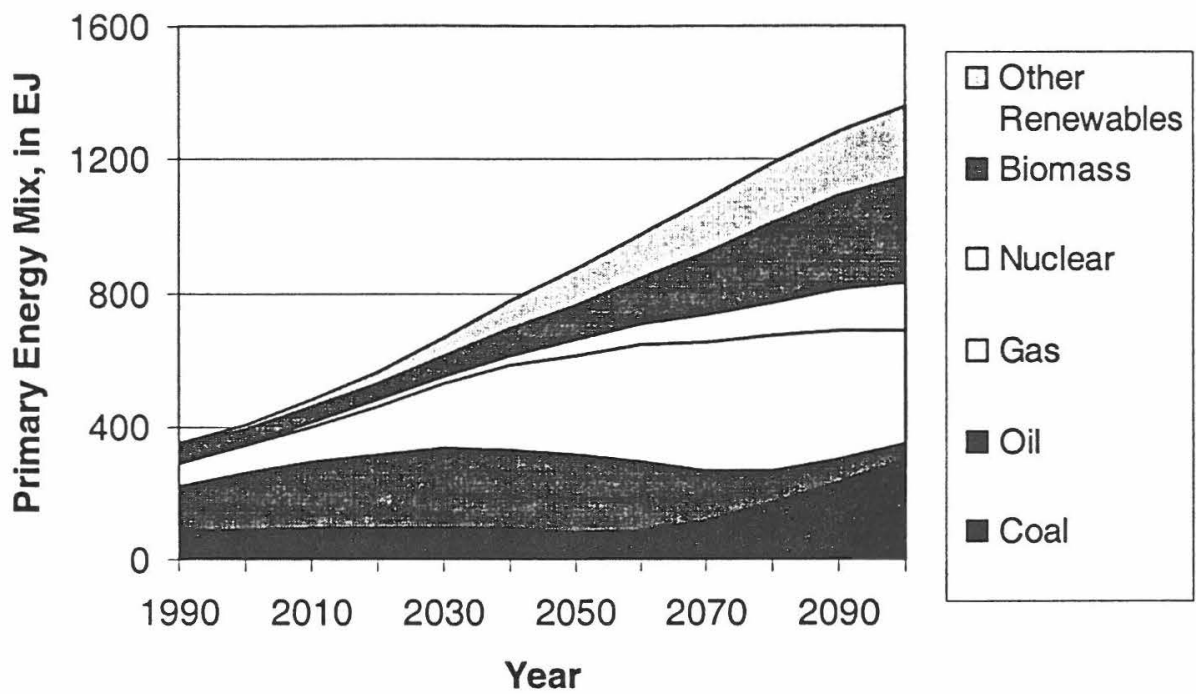

Fig. 7. Global primary energy mix for the B2 scenario. Primary energy was calculated by using the direct equivalent method for all non-thermal uses of renewables and nuclear.

A major additional characteristic of the B2 scenario is the growing importance of synthetic liquid fuels in the second half of the next century. This is shown in Figure 8 and is due to the steady phase-out of oil in all regions.

Differences persist among regional primary energy structures right through 2100 . This reflects both the different regional endowments of energy resources and the B2 storyline's emphasis on regional self-reliance and lack of rapid inter-regional technology diffusion. Low-income regions with high resource availability continue to rely on fossil fuels. Examples are China's reliance on coal, the former Soviet Union's reliance on principally gas, and the Middle East's reliance on first oil and later gas. Poor regions with low resource availability, such as Africa and South America, rely increasingly on locally available renewables. The share of coal and oil in the primary energy structures

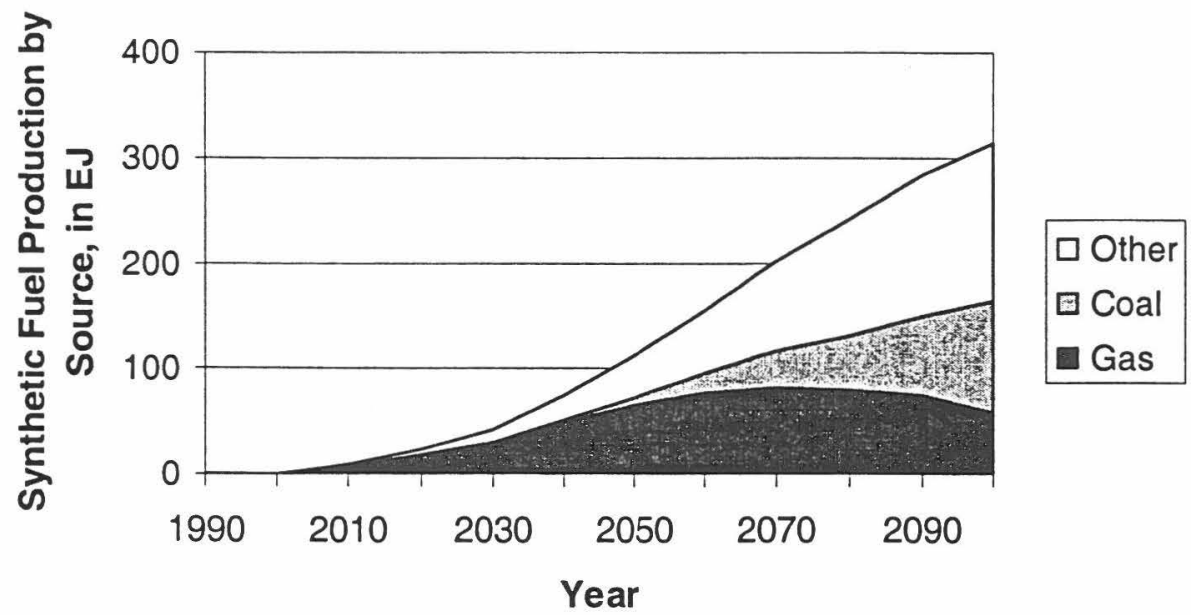

Fig. 8. Synthetic fuel production by source in the B2 scenario. 


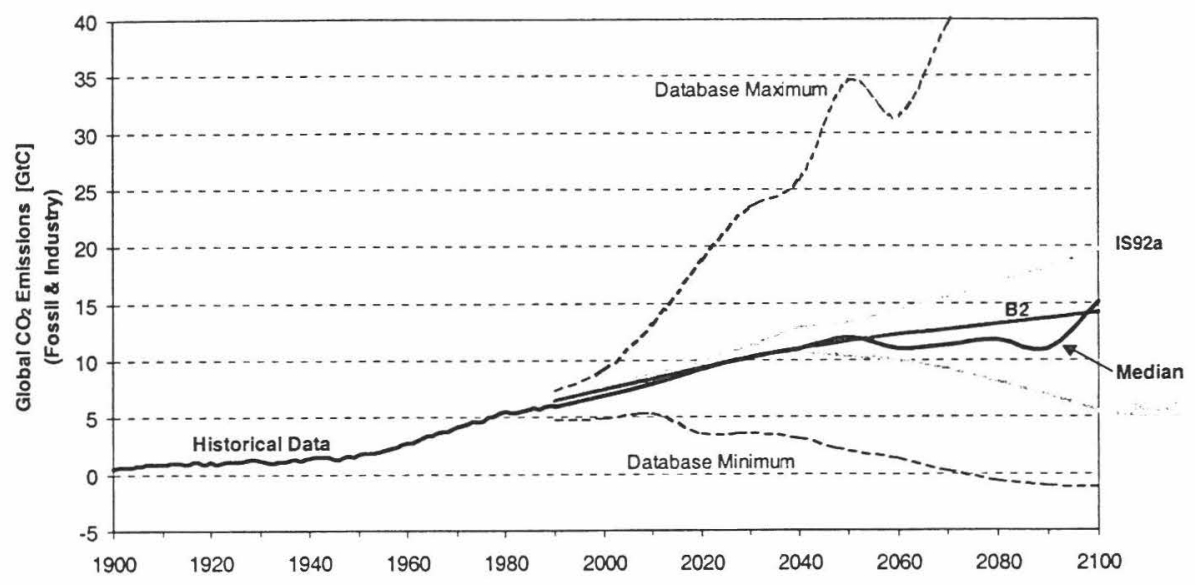

Fig. 9. Global carbon emissions from fossil fuel combustion and industrial sources. Historical development from 1900 to 1990 and future trajectories for the B2, IS92a, and B2S550 scenarios. Also shown is the median of the $\mathbf{2 5 6}$ scenarios in Morita and Lee's database that report global carbon emissions.

of industrialized countries decreases. The importance of renewables, gas, and nuclear power grows correspondingly.

\section{5 $\mathrm{CO}_{2}$ EMISSIONS AND CARBON CONCENTRATIONS}

Carbon dioxide is the most important contributor to anthropogenic changes in atmospheric radiative forcing. The main sources of anthropogenic $\mathrm{CO}_{2}$ emissions are the burning of fossil fuels (6.2 GtC in 1990) and the net release of carbon from landuse changes (1.0 GtC in 1990). Smaller anthropogenic sources are cement production (0.2 GtC in 1990) and gas flaring (less that $0.1 \mathrm{GtC}$ in 1990). In the B2 scenario total anthropogenic carbon emissions increase slowly but steadily to $14.2 \mathrm{GtC}$ in 2100 . This figure is for gross $\mathrm{CO}_{2}$ emissions, defined as $\mathrm{CO}_{2}$ emissions from fossil fuels (including feedstocks), industrial sources, and land-use change. While gross carbon emissions increase, however, carbon intensity in the B2 scenario declines from $21 \mathrm{tC} / \mathrm{TJ}$ in 1990 to $10 \mathrm{tC} / \mathrm{TJ}$ in 2100 , reflecting both technological and economic changes.

As shown in Figure 9 the B2 scenario's total anthropogenic carbon emissions are close to the median of $15 \mathrm{GtC}$ for the 256 scenarios in Morita and Lee's database that report $\mathrm{CO}_{2}$ emissions. Also shown in the figure are the significantly higher carbon emissions of the IS92a scenario, which reach $20 \mathrm{GtC}$ in 2100 , and the trajectory for the B2S550 scenario that will be discussed in Section 7.

For the $\mathrm{B} 2$ scenario the atmospheric $\mathrm{CO}_{2}$ concentration increases from about 355 ppmv in 1990 to slightly above 600 ppmv in 2100 . Although the concentration in 2100 is about 100 ppmv lower than in the IS92a scenario, the B2 scenario's trajectory suggests a continuing increase beyond 2100 and a significant global warning effect (see Section 7.2). Figure 10 shows the projected carbon concentrations in the B2, B2S550, and IS92a scenarios.

\section{6 $\mathrm{CH}_{4}$ EMISSIONS}

With the growing use of fossil fuels in the $\mathrm{B} 2$ scenario, $\mathrm{CH}_{4}$ emissions from the energy sector rise from 68 megatons of methane $\left(\mathrm{MtCH}_{4}\right)$ in 1990 to about $187 \mathrm{MtCH}_{4}$ in 2100 (see Table 6). As surface coal mines become gradually depleted, mining shifts to deeper coal with higher $\mathrm{CH}_{4}$ emission coefficients. This effect is essentially balanced 


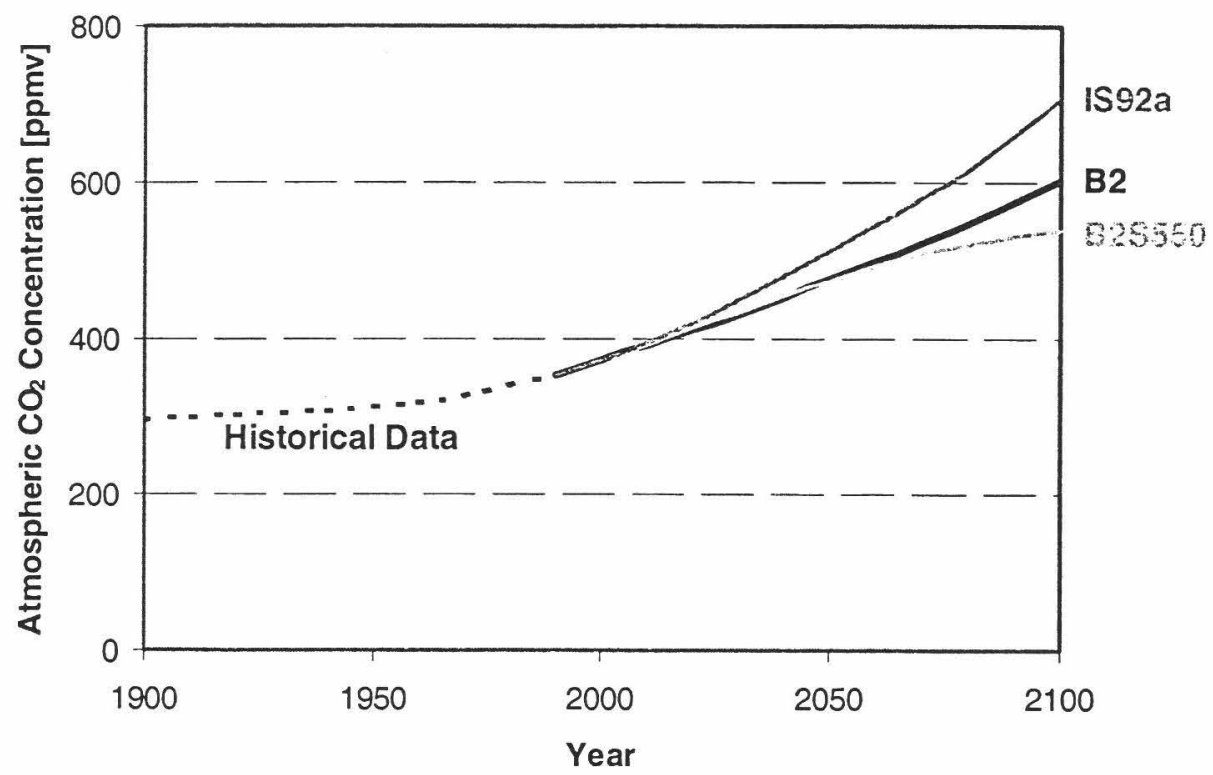

Fig. 10. Atmospheric Co $\mathrm{Co}_{2}$ concentrations. Historical development from 1900 to 1990 and future trajectories for the B2, IS92a, and B2S550 scenarios.

out by assumed increases in the recovery of $\mathrm{CH}_{4}$ from deep coal mines to be used as an energy source. Thus the global methane emission coefficient per unit of coal stays roughly constant at about $0.4 \mathrm{kgCH}_{4} / \mathrm{GJ}$. Methane emissions from the use of coal therefore grow roughly in parallel with coal consumption. Reflecting the initially unchanging level of coal use in Figure 7, global methane emissions from coal use are stable at about $34 \mathrm{MtCH}_{4}$ in the first half of next century. They then increase to 120 $\mathrm{MtCH}_{\downarrow}$ in 2100 due to the growing demand for coal for producing a synthetic liquid fuel.

Because of gradual technological improvements in the gas sector (e.g., reduced pipeline leakage). the aggregated emission coefficient for gas decreases from $0.39 \mathrm{kgCH}_{4} /$ GJ in 1990 to about $0.2 \mathrm{kgCH}_{4} / \mathrm{GJ}$. As a result, absolute emissions from gas increase slower than gas consumption, from $26 \mathrm{MtCH}_{4}$ in 1990 to $64 \mathrm{MtCH}_{4}$ in 2100 . Emissions from oil extraction show a peak around 2030 at $13 \mathrm{MtCH}_{4}$, then drop to $2 \mathrm{MtCH}_{4}$ in 2100 as oil is steadily phased out.

Non-energy emissions from rice paddies, enteric fermentation, non-energy biomass burning, agricultural waste burning, landfills and sewage were taken from Morita et al.'s quantification of the B2 storyline using the AIM model [26]. The resulting aggregated per capita emission coefficient for non-energy emissions decreases moderately from 47 $\mathrm{kgCH}_{4}$ per capita to about $38 \mathrm{kgCH}_{4}$ per capita in 2100 . This corresponds to total emissions growing from $232 \mathrm{MtCH}_{4}$ in 1990 to $387 \mathrm{MtCH}_{4}$ in 2100 (see Table 6).

\subsection{SO, EMISSIONS}

Sulfur oxide emissions $\left(\mathrm{SO}_{x}\right)$ both influence the climate system and impact local and regional human health, food security, and ecosystems. In 1990 the main sources of anthropogenic $\mathrm{SO}_{\mathrm{v}}$ emissions were energy-related coal combustion (39 $\mathrm{MtS}$ ) and oil combustion (17 MtS) and, to a lesser extent, industrial activities ( $8 \mathrm{MtS})$, biofuel combustion ( $2 \mathrm{MtS}$ ), and international shipping ( $3 \mathrm{MtS}$ ). In the B2 scenario, with its emphasis on regional environmental protection, we assume that the constraints and technologies 
TABLE 6

Anthropogenic Methane Emissions in the B2 Scenario

\begin{tabular}{|c|c|c|c|c|c|}
\hline & \multicolumn{5}{|c|}{ B2 - Anthropogenic emissions } \\
\hline & Unit & 1990 & 2020 & 2050 & 2100 \\
\hline $\mathrm{CH}_{4}$ Emissions & $\mathrm{MtCH}_{4}$ & 299.5 & 363.9 & 483.7 & 574.3 \\
\hline Energy-related" & & 67.7 & 84.6 & 103.5 & 187.0 \\
\hline Coal mining & & 33.8 & 36.5 & 31.7 & 120.3 \\
\hline Natural gas (pipeline leakages etc.) & & 25.5 & 35.8 & 60.1 & 63.8 \\
\hline Oil extraction & & 8.3 & 12.1 & 11.4 & 1.8 \\
\hline Biomass & & 0.02 & 0.23 & 0.33 & 1.07 \\
\hline Non-energy-related ${ }^{h}$ & & 231.8 & 279.3 & 380.2 & 387.3 \\
\hline Cultivated land & & 59.8 & 62.6 & 66.2 & 73.0 \\
\hline Biofuel resident & & 7.0 & 7.4 & 7.8 & 8.6 \\
\hline Enteric fermentation & & 80.3 & 82.0 & 84.0 & 87.2 \\
\hline Deforestation and its relations & & 24.0 & 1.4 & 0.0 & 0.0 \\
\hline Landfills and sewage & & 60.7 & 125.9 & 222.2 & 218.4 \\
\hline
\end{tabular}

'Directly from MESSAGE output.

${ }^{\mathrm{h}}$ Non-energy related emissions for $\mathrm{CH}_{4}$ were taken from the AIM B2 run.

that reduce sulfur emissions under the Clean Air Act Amendments in the United States and the Second Sulfur Protocol in Europe are essentially extended and even tightened. More specifically, all new coal-fired power plants after 2050 are required to incorporate state-of-the-art desulferization technology in all regions.

Energy-related sulfur emissions calculated by the MESSAGE model decline slowly but steadily from $59 \mathrm{MtS}$ in 1990 to about $12 \mathrm{MtS}$ in 2100 . Through mid-century emissions decrease as, first. growing incomes in developing countries lead to higher-quality energy forms replacing direct uses of solid fuels such as coal and fuelwood. Second, a transition takes place in the electricity sector to clean coal technologies, such as IGCC power plants. The aggregated emission coefficient for power production from coal declines from $4.5 \mathrm{kgS} / \mathrm{MWh}$ to $0.04 \mathrm{kgS} / \mathrm{MWh}$ by 2100 , a level similar to the most advanced current technologies, e.g.. the IGCC98 power plant by SIEMENS at $0.032 \mathrm{kgS} / \mathrm{MWh}$ [27]. In the second half of the century, desulfurization of the energy system also takes place at the level of synthetic liquid fuel production (methanol) from coal. Methanol is mainly used in the transport sector as a substitute for the oil products that become scarce after 2050. Taken together, these factors cause energy-related sulfur emissions in the low-income regions (ASIA and ALM) to initially increase at the beginning of next century, then peak, and begin a long-term decline. In the high-income regions (OECD90 and REF) sulfur emissions have already passed their peaks, and they continue to decline throughout the B2 scenario.

Emissions from industrial activities were calculated as described in Section 5 and grow in the first half of next century from about $8 \mathrm{MtS}$ in 1990 to stabilize at about 30 MtS by 2050. The method for calculating sulfur emissions from non-energy related biomass burning was also described in Section 5. It leads to sulfur emissions that remain essentially flat through the whole B2 scenario at about the same level as today, $2 \mathrm{MtS}$. Sulfur emissions from international shipping (bunker fuels) were assumed to remain constant at the current level of $3 \mathrm{MtS}$.

The overall result is that total sulfur emissions initially increase in the B2 scenario in today's developing countries, particularly in Asia, but these increases are effectively offset by decreases in industrialized countries. As a result, global sulfur emissions in the B2 scenario stay roughly constant from 1990 to 2020 . They then decline to some 

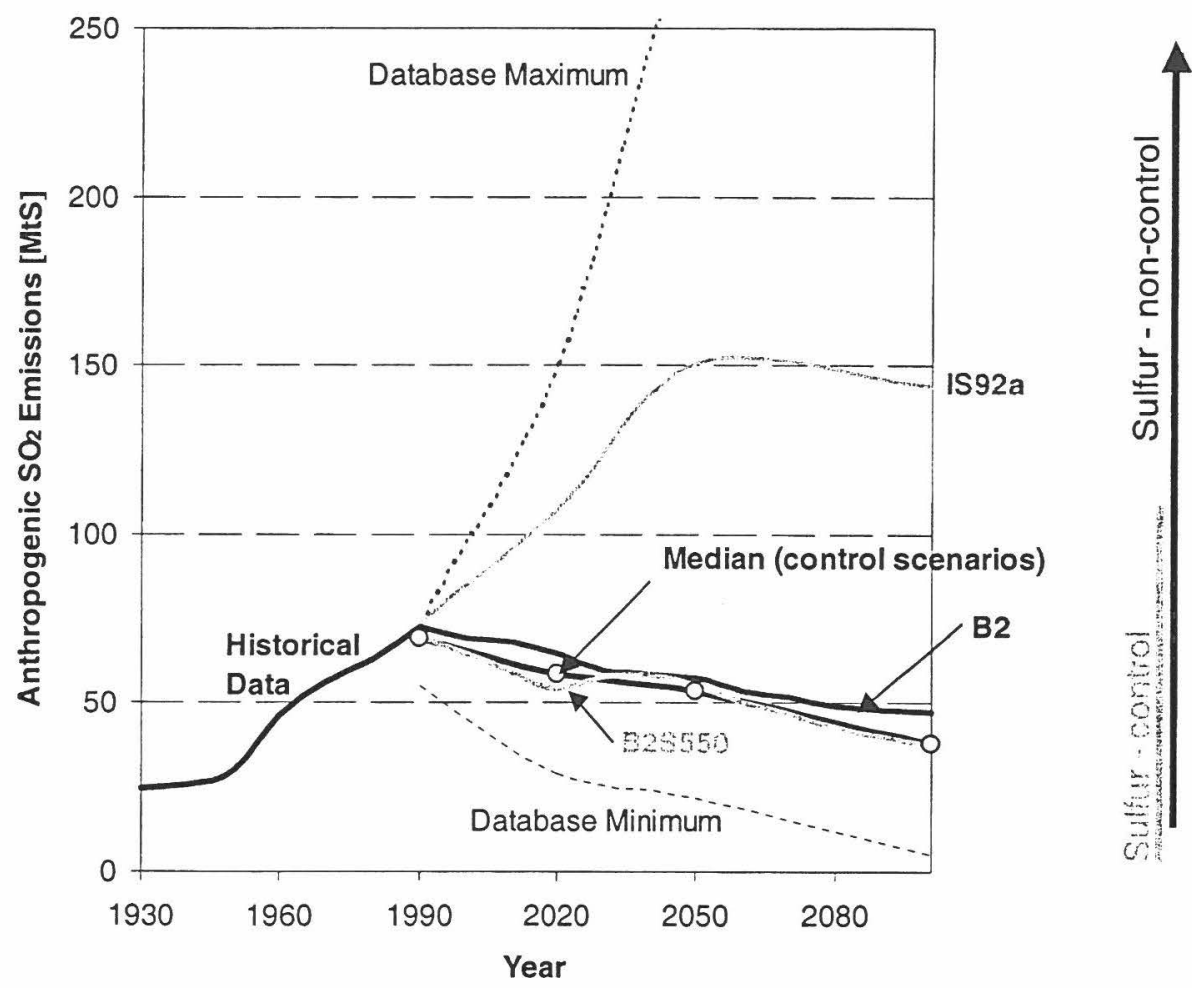

Fig. 11. Global anthropogenic sulfur emissions. Historical development from 1930 to 1990 and future trajectories for the B2, IS92a, and B2S550 scenarios. Also shown is the median of the scenarios from [28].

$50 \mathrm{MtS}$ by 2050 and $43 \mathrm{MtS}$ by 2100 . This is close to the median of all recently published sulfur mitigation studies as discussed by Grübler [28]. Figure 11 shows the sulfur emission trajectories for the B2, IS92a, and B2S550 scenarios. Both the B2 and B2S550 scenarios have significantly lower sulfur emissions than any of the IS92 scenarios [2], which emit 80 to $200 \mathrm{MtS}$ in 2050 and 60 to $230 \mathrm{MtS}$ by 2100 . Table 7 provides a sectoral breakdown of both energy and non-energy related sulfur emissions for the B2 scenario.

Finally, for estimates of anthropogenic emissions of $\mathrm{N}_{2} \mathrm{O}$, halocarbons, $\mathrm{NO}_{w}$, and VOCs the reader is referred to Tables 4 and 5 in Section 5. Section 5 also discusses the methods by which these estimates were developed.

\section{The B2S550 Scenario: Stabilizing Carbon at 550 ppmv}

\subsection{B2S550 SCENARIO}

Because GHG emissions in the B2 scenario continue to climb steadily right through 2100 (see particularly Figure 9), the B2 scenario offers no promise of climate stabilization. To learn what actions might be required for climate stabilization in a future comparable to the B2 storyline, we therefore developed a carbon-constrained variation of the B2 scenario. This we call the B2S550 scenario. It is constrained to stabilize the atmospheric $\mathrm{CO}_{2}$ concentration at approximately $550 \mathrm{ppmv}^{8}[29]$ in the year 2100 (see Figure 10).

" 550 ppmv is simply the middle of five stabilization levels analyzed by Wigley et al. [29]. We choose it here for illustrative purposes only and do not propose to argue that it would necessarily satisfy the UNFCCC objective of preventing "dangerous anthropogenic interference with the climate system." 
TABLE 7

Anthropogenic Sulfur Emissions in the B2 Scenario (Sectoral Breakdown)

\begin{tabular}{|c|c|c|c|c|c|}
\hline & \multicolumn{5}{|c|}{ B2 - Anthropogenic emissions } \\
\hline & Unit & 1990 & 2020 & 2050 & 2100 \\
\hline $\mathrm{SO}_{2}$ emissions, world & $\mathrm{MtS}$ & 68.97 & 62.95 & 54.07 & 44.91 \\
\hline Energy-related ${ }^{a}$ & & 58.50 & 42.84 & 21.37 & 12.32 \\
\hline Coal & & 39.23 & 28.08 & 10.87 & 7.47 \\
\hline Oil & & 17.50 & 13.07 & 8.79 & 2.39 \\
\hline Gas & & 0.08 & 0.25 & 0.45 & 0.55 \\
\hline Biomass & & 1.70 & 1.44 & 1.26 & 1.91 \\
\hline Non-energy-related & & 10.47 & 20.11 & 32.70 & 32.59 \\
\hline Industrial Processes ${ }^{h}$ & & 8.10 & 17.79 & 30.30 & 30.11 \\
\hline Biomass Burning ${ }^{\mathrm{c}}$ & & 2.37 & 2.32 & 2.39 & 2.48 \\
\hline $\mathrm{SO}_{2}$ emissions, $\mathrm{OECD} 90$ & & 26.20 & 9.26 & 5.66 & 3.50 \\
\hline $\mathrm{SO}_{2}$ emissions, $\mathrm{REF}$ & & 16.77 & 6.12 & 4.51 & 3.61 \\
\hline $\mathrm{SO}_{2}$ emissions, ASIA & & 17.33 & 31.80 & 25.73 & 20.60 \\
\hline $\mathrm{SO}_{2}$ emissions, ALM & & 8.71 & 12.62 & 17.73 & 17.20 \\
\hline
\end{tabular}

a Directly from MESSAGE output.

${ }^{n}$ Final energy industrial thermal (a proxy for heavy industry) from MESSAGE linked to the base year emission activities from the EDGAR database.

' Forest area from AIM B2 run linked to the base year emission activities from the EDGAR database.

The constraint of $550 \mathrm{ppmv}$ in 2100 was first translated into linear emission constraints in each of the ten-year time steps used in MESSAGE. This was done using weighting factors representing the contributions that emissions in each time step make to the carbon concentration in 2100 . The weighting factors effectively constitute a linear approximation of the carbon cycle, i.e., the time profile by which a unit a $\mathrm{CO}_{2}$ emitted into the atmosphere is absorbed by a variety of sinks, most notably the oceans. The weighting factors were determined according to the method developed by Akimoto [30].

The results presented below are based on iterated runs of MESSAGE and MACRO. The macroeconomic model MACRO is important because the carbon constraint drives up energy costs, which will drive down energy demand, other things being equal. MACRO calculates this macroeconomic effect. Because both MESSAGE and MACRO are global optimization models, the results below assume that the actions taken to meet the B2S550 scenario's carbon constraint are those that MESSAGE and MACRO determine to be globally least costly. The results assume full spatial and temporal flexibility and the ability to freely move investment funds from where they are available to where they are needed. However, the cheapest opportunities to cut carbon emissions will not always be in regions that give high priority to such reductions and have the money to pay for them. Indeed the cheapest carbon reduction opportunities at the moment appear to be in developing countries while it is the developed countries that currently appear most willing to pay. The B2S550 scenario can thus be seen as a possible answer to the question, "How might stabilization be achieved if a world generally consistent with the B2 storyline were able to successfully coordinate and cooperate on efforts to limit potential global warming?"

The B2S550 scenario also assumes that all GHG emissions calculated outside of MESSAGE are the same as in the $\mathrm{B} 2$ scenario, and only $\mathrm{CO}_{2}$ emissions covered by MESSAGE can be reduced in order to meet the $550 \mathrm{ppmv}$ constraint. In this the results are conservative. They ignore the possibilities of land-use changes, non-energy related reductions, and reductions in GHGs not covered by MESSAGE that might prove cheaper than the reductions chosen by MESSAGE. They thus represent a lower bound on allowable $\mathrm{CO}_{2}$ emissions from the energy sector. 
Sources of $\mathrm{CO}_{2}$ Reduction:

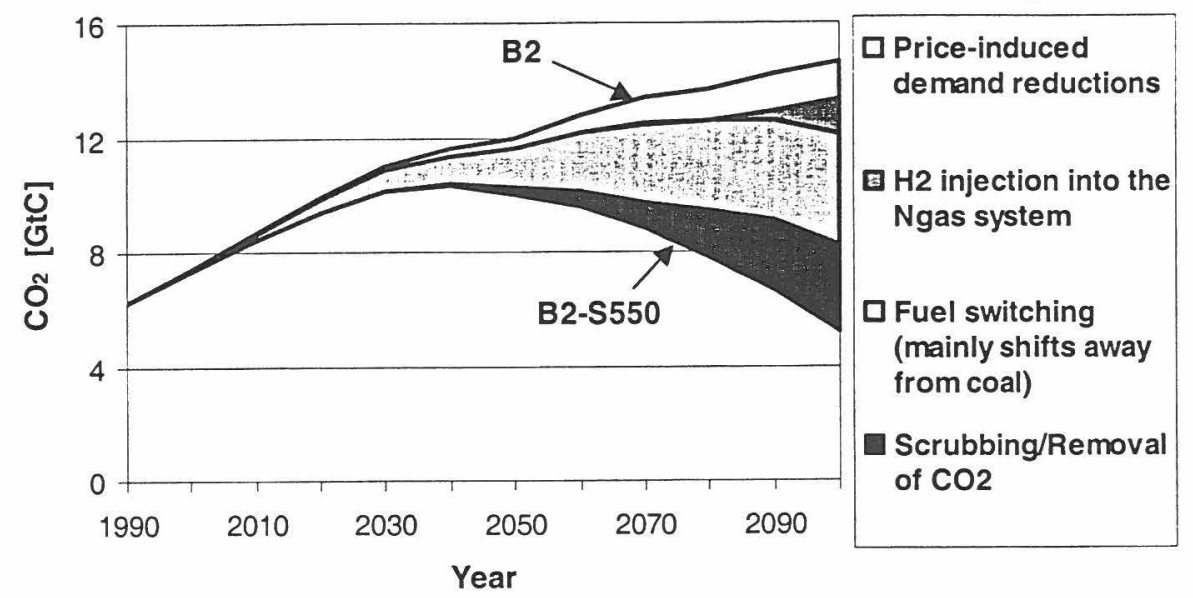

Fig. 12. $\mathrm{CO}_{2}$ emissions in the $\mathrm{B} 2$ and $\mathrm{B} 2 \mathrm{~S} 550$ scenarios, and the four main components of the B2S550 scenario's carbon reductions. The structural switch away from coal, carbon scrubbing, and enhanced energy conservation account for the bulk of the reductions.

Figure 12 compares $\mathrm{CO}_{2}$ emissions in the $\mathrm{B} 2 \mathrm{~S} 550$ and B2 scenarios. Through 2020 emissions are similar in both scenarios. Partly this is because power plants have lifetimes on the order of 30-40 years, which makes for slow turnover in the energy capital stock. Partly it results from the temporal flexibility built into the concentration constraint. MESSAGE is free to choose when to reduce carbon emissions, and later reductions coinciding with turnover in capital plant are usually cheaper, because of both technological progress and discounting. After $2020 \mathrm{CO}_{2}$ emissions decline rapidly in the B2S550 scenario to $5.2 \mathrm{GtC}$ in 2100 .

Figure 12 also indicates the four main changes in the energy system that MESSAGE and MACRO identify as the most cost-effective route to meeting the carbon constraint.

- Fuel switching away from carbon-intensive fuels such as coal.

- Scrubbing and removing $\mathrm{CO}_{2}$ in power plants and during the production of synthetic fuels, mainly methanol, and hydrogen.

- Low energy demand (enhanced energy conservation) due to higher energy costs than in the B2 scenario.

- Decarbonization of the natural gas system via hydrogen injection.

The largest contribution comes from structural changes in the energy system, principally a shift away from coal. This is due to the increasing cost of coal, which has the highest $\mathrm{CO}_{2}$ emissions per unit of energy. To satisfy the carbon constraint, the B2S550 scenario makes a pronounced shift to less carbon-intensive resources, and coal's share of primary energy decreases from $26 \%$ in 1990 to $6 \%$ in 2100 . This is much lower than its $22 \%$ share in the B2 scenario in 2100. The shift is largest in the ASIA and ALM regions due to the rapid turnover associated with their high growth rates. Rapid turnover creates greater opportunities to move away from a traditional coal economy. The shift away from coal also leads to additional reductions in energy-related emissions of sulfur (see Figure 11) and methane compared to the $\mathrm{B} 2$ scenario. As was the case for $\mathrm{CO}_{2}$, energy-related sulfur and methane reductions are moderate during the first half of the 
TABLE 8

GWP Losses, in Percentage of the B2 Scenario's GWP, and Global Carbon Reduction Costs in US\$(1990)/tC for the B2S550 Scenario Relative to B2

\begin{tabular}{ccc}
\hline Year & $\begin{array}{c}\text { GDP loss } \\
(\%)\end{array}$ & $\begin{array}{c}\text { Macroeconomic reduction cost } \\
\text { US } \$(1990) / \text { tC }\end{array}$ \\
\hline 1990 & 0.0 & 0 \\
2020 & 0.1 & 140 \\
2050 & 0.4 & $\sim 250$ \\
2100 & 1.7 & $<500$ \\
\hline
\end{tabular}

next century (about $10 \%$ below B2 emissions in 2050) and later become more substantial. By 2100 they are almost $50 \%$ below the B2 scenario.

Carbon scrubbing is the second most important source of $\mathrm{CO}_{2}$ emission reductions in the B2S550 scenario. Carbon scrubbing is applied to hydrogen and synfuels production (1.6 GtC in 2100) and electricity production (1.4 GtC in 2100). Even with the penalty that $\mathrm{CO}_{2}$ scrubbing entails in the form of additional costs and electricity losses, it remains a relatively attractive option because of readily available, extensive coal resources.

The third most important source of $\mathrm{CO}_{2}$ emission reductions is price-induced energy demand reductions. The increased cost of energy resulting from the carbon constraint leads to lower GWP growth, which leads to lower energy demand growth. Slower GWP growth becomes noticeable after 2020, and by 2100 the GWP gap between the B2 and B2S550 scenarios is about $1.7 \%$ of the B2 scenario's GWP. This is comparable to results from similar studies. Edmonds and Richels [31], for example, report losses of 0.5 to $1 \%$ for a $500 \mathrm{ppm}$ stabilization constraint. Results for a $550 \mathrm{ppmv}$ stabilization case from the 14th Energy Modeling Forum for four different models (CSERGE, CETA, PEF, and CONN) suggest losses between 0.4 and $3.4 \%$ of GWP [32]. These losses are still rather small compared to the GWP increase in the B2 scenario - GWP in 2100 is 11.7 times as large as in 1990. Table 8 summarizes the calculated GWP differences between the B2 and B2S550 scenarios. It includes the estimated macroeconomic cost (i.e., the GWP loss) per ton of carbon reduction. This increases from US\$0/tC in 1990 to about US $\$ 140 / \mathrm{tC}$ in 2020 and a bit less than US $\$ 500 / \mathrm{tC}$ in 2100 .

Finally, late in the century, a small contribution to carbon reductions arises from hydrogen injection into the natural gas system [33]. Here, $\mathrm{CO}_{2}$ emission coefficient of natural gas is reduced by mixing it either with hydrogen from carbon-free sources (mainly solar-thermal power plants) or, in a transition phase, with hydrogen produced by steam reforming natural gas (and sequestering the associated $\mathrm{CO}_{2}$ ). The $\mathrm{B} 2 \mathrm{~S} 550$ scenario allows hydrogen to be injected up to a level of about $15 \%$ of the overall resulting natural gas-hydrogen mix. $15 \%$ is within the $15-20 \%$ range used in many current initiatives for hythane powered vehicles today. Such a mixture of methane and hydrogen shipped via gas pipelines hardly qualifies as a radical new technology considering that coal-derived town gas, itself just a mixture of hydrogen and methane, was the dominant gaseous fuel in cities prior to natural gas. It also has the advantage that it needs no new capital-intensive infrastructures. Concerns might exist about hydrogen embrittlement in old pipeline systems, but standards for modern pipelines are sufficiently high that embrittlement should not be a concern, particularly by 2085 when Figure 12 shows hydrogen injection starting to make a dent.

\subsection{RADIATIVE FORCING AND TEMPERATURE CHANGE}

For the calculation of radiative forcing and temperature changes, energy-related emissions were added to non-energy emissions and input into the MAGICC model. 


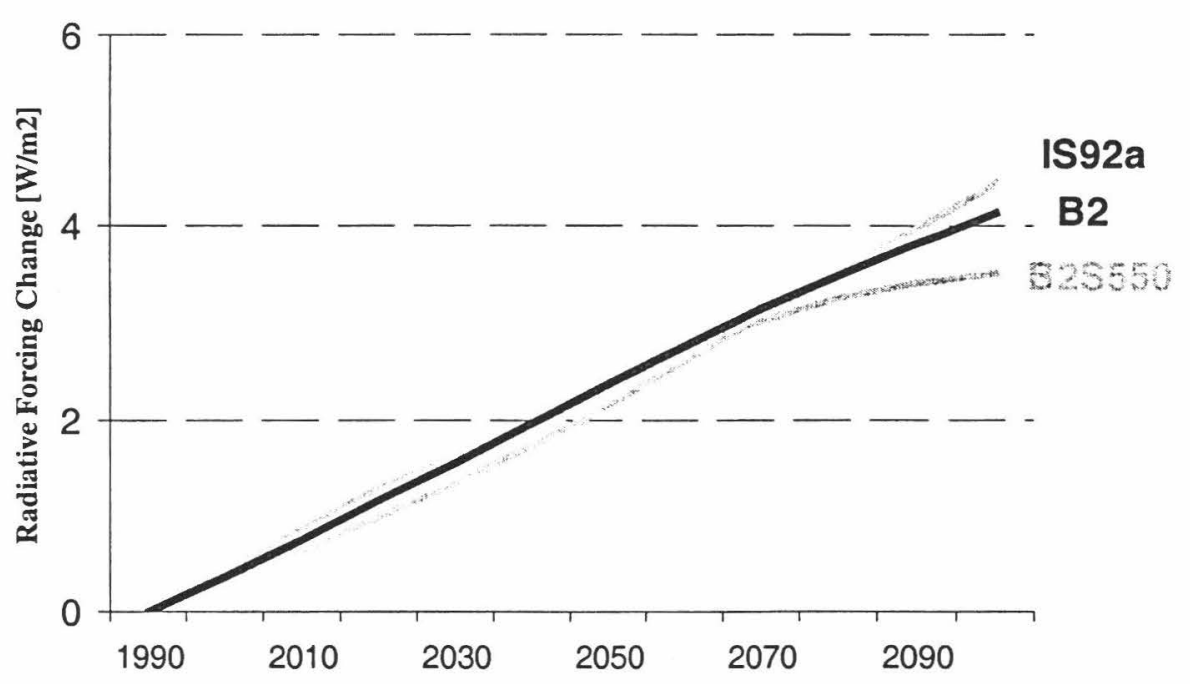

Fig. 13. Global radiative forcing change relative to 1990 for the B2, B2S550, and the IS92a scenarios.

Figure 13 shows the resulting changes in relative radiative forcing from 1990 to 2100 for the B2, B2S550, and IS92a scenarios. In 2100, the increase in radiative forcing relative to 1990 for all GHGs and sulfur aerosols is about $4.2 \mathrm{~W} / \mathrm{m}^{2}$ in the B2 scenario. This corresponds to a growth rate of about $1 \%$ per year. By 2100 the rise in radiative forcing in the $\mathrm{B} 2$ scenario is due $70 \%$ to $\mathrm{CO}_{2}$ increases, $10 \%$ to $\mathrm{CH}_{4}$ increases, $6 \%$ to CFC increases, and $9 \%$ to sulfur aerosol decreases.

As shown in Figure 13 the relative radiative forcing for the B2 and IS92a scenarios is about the same in 2100, although the $\mathrm{B} 2$ scenario's $\mathrm{CO}_{2}$ concentration ( 600 ppmv in 2100 ) is significantly below that of the IS92a scenario (700 ppmv). The explanation is the different sulfur aerosol emissions in the scenarios. Sulfur emissions in the IS92a scenario double by 2100 relative to 1990 , while those in the B2 scenario decrease by half. Hence the lower warming effects of $\mathrm{CO}_{2}$ in the $\mathrm{B} 2$ scenario relative to the IS $92 \mathrm{a}$ scenario are offset by the lower sulfate cooling effects as well. Overall, the two scenarios have very similar radiative forcing profiles. In considering this result, however, it is important to keep in mind that the impact of sulfur on climate is much more complex that the impact of carbon, since sulfur is distributed much less evenly around the world. Thus while sulfur may impact global averages as shown in Figure 13, its regional effects are likely to be more varied and less predictable.

Figure 14 depicts the best guess estimates ${ }^{9}$ of the global mean temperature change for the B2, B2S550, and IS92a scenarios and compares them to the uncertainty range for the B2 scenario. The best guess estimates for global mean temperature change of the B2 and IS92a scenarios increase to about $2^{\circ} \mathrm{C}$ from 1990 to 2100 , compared to a best guess estimate of $1.8^{\circ} \mathrm{C}$ for the $\mathrm{B} 2 \mathrm{~S} 550$ scenario. The scenarios span a comparatively small range compared to the climate sensitivity uncertainty for the $\mathrm{B} 2$ scenario, which ranges from $1.4^{\circ} \mathrm{C}$ to $2.9^{\circ} \mathrm{C}$ in 2100 .

${ }^{9}$ See Footnote 1 for an explanation of best guess estimates of global mean temperature and their uncertainty ranges. 


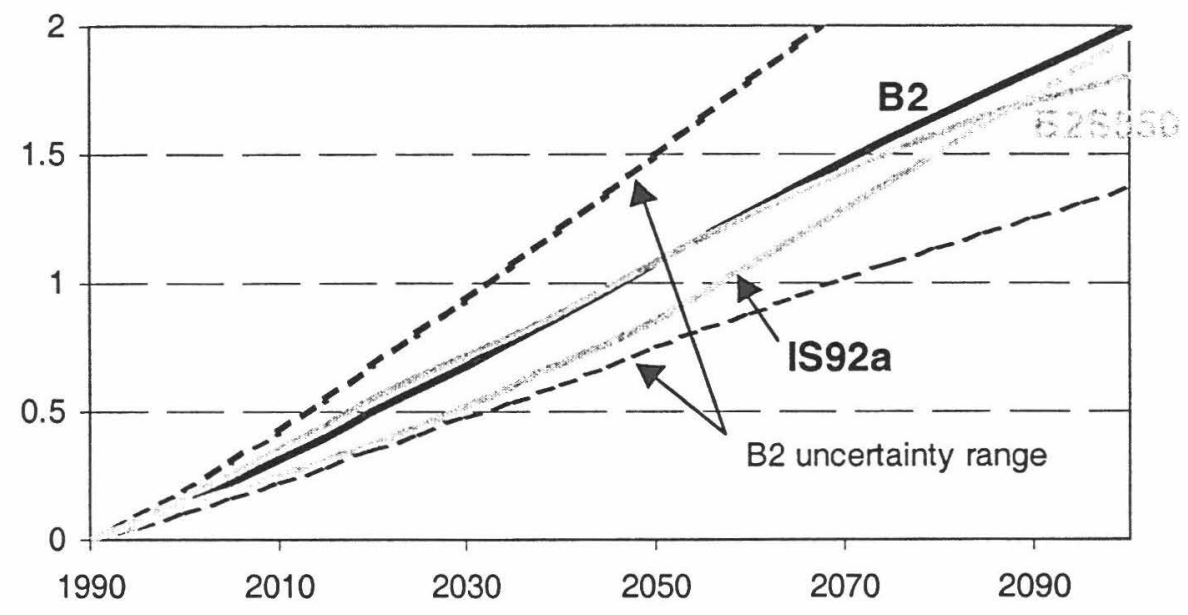

Fig. 14. Global mean temperature change: best guess estimates for the B2, B2S550, and the IS92a scenarios compared to the uncertainty range for the $\mathrm{B} 2$ scenario, i.e., corresponding to a variation of the climate sensitivity parameter between $1.5^{\circ} \mathrm{C}$ and $4^{\circ} \mathrm{C}$.

\section{Conclusion}

This article presents one possible quantification of the B2-storyline described in Section 2. The B2 storyline complements the A1, A2, and B1 storylines described elsewhere in this issue. As inputs we used the UN's median population projection plus economic growth rates that are consistent with the UN population projection and with historical correlations in the Scenario Generator, and that lead to global economic growth approximating the median in Morita and Lee's database [1]. We have characterized the cost reduction rates in the B2 scenario as "dynamics-as-usual." With a few specific exceptions, initial technology costs and future cost reduction rates were taken from IIASA's CO2DB and from the IIASA-WEC Case B. The few exceptions are the assumed initial costs and subsequent cost reductions for particularly non-sulfur-emitting technologies, which were revised to reflect more recent and more promising performance projections. These non-sulfur-emitting technologies include in particular wind and solar photovoltaics, but also gas combined cycle, integrated gasification combined cycle, solar thermal power plants, and advanced nuclear power plants. For conventional coal technologies, on the other hand, future extraction and conversion costs are less optimistic than in the IIASA-WEC Case B.

Global carbon emissions from energy use and industrial sources in this quantification of the B2 scenario rise from $6.5 \mathrm{GtC}$ in 1990 to $14.2 \mathrm{GtC}$ in 2100 . Primary energy use climbs from $350 \mathrm{EJ}$ to $1360 \mathrm{EJ}$. The global primary energy structure shifts away from gas and oil (28\% in 2100 compared to $55 \%$ in 1990) and towards non-fossil energy sources ( $50 \%$ in 2100 compared to $18 \%$ in 1990). The share of coal is $22 \%$ in 2100 , only four percentage points lower than in 1990. Synthetic liquid fuel production grows to $330 \mathrm{EJ}$ in 2100 , driven largely by assumptions about the long-term decline of oil and a continuation in current trends towards increasingly flexible, convenient, and cleaner forms of final energy. Sulfur emissions decline from $69 \mathrm{MtS}$ in 1990 to $45 \mathrm{MtS}$ in 2100. Global radiative forcing grows by approximately $1 \%$ per year from 1990 through 2100 . The best guess temperature change associated with this increase in radiative forcing is $2^{\circ} \mathrm{C}$ in 2100 . 


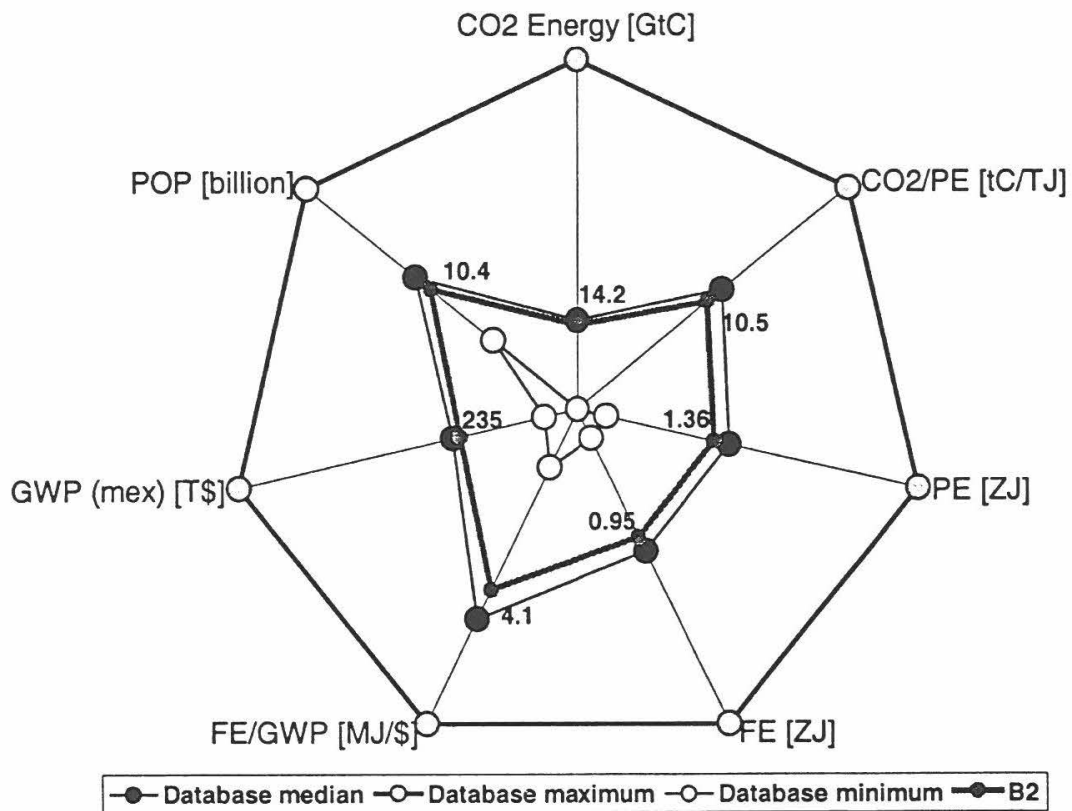

Fig. 15. Global scenario ranges for the year 2100. In the form of a "snowflake" the main indicator values of the $\mathrm{B} 2$ scenario are compared to the minimum, maximum, and median values from Morita and Lee's database.

In terms of energy intensity, energy consumption growth, carbon intensity, and $\mathrm{CO}_{2}$ emissions in 2100 , the $\mathrm{B} 2$ scenario stays close to the global medians of the scenarios in Morita and Lee's database [1]. Sulfur emissions approximate the median of all recently published sulfur mitigation studies as discussed by Grübler [28]. Figure 15 compares the main global scenario indicators of the B2 scenario to the database medians for the year 2100. At the regional level, however, the B2 scenario deviates from the database medians. There are two reasons. First, regional medians generally do not add up to global medians so it is not possible to create a scenario which corresponds to the global and regional medians at the same time. Second, the regional medians from the scenario database do not match the B2 storyline, which includes gradually increasing equity and conditional convergence between industrialized and developing countries over the next century.

Compared to the IS92a scenario, the B2 scenario reflects higher resource estimates in the more recent literature [22] and assumes faster future progress in the technologies to exploit these resources. Plus the B2 scenario assumes that additional unconventional resource categories will become available over the next century due to technological progress. Altogether, resource availability assumptions in the B2 scenario exceed those in the IS92a scenario by a factor of 1.6 for oil and by a factor of about two for gas. More generally, the dynamics-as-usual technology inputs of the B2 scenario distinguish it from the static assumptions used in the IS92a scenario. Both the B2 and the IS92a scenarios result in long-term declines in primary energy intensity that annually average about $1 \%$, similar to the long-term historical average in countries with sufficiently long time series of data to compute a long-term average $[8,34]$. One might have expected that including technology improvements in the B2 scenario, in contrast to IS92a's static 
technology assumptions, would have led to a faster decline in the B2 scenario's primary energy intensity. But what happens is that the advantage of dynamic technology in the B2 scenario goes to buying a higher quality mix of final energy forms. The rate at which the primary energy intensity declines stays essentially unchanged.

The B2 scenario also differs from the IS92a scenario in terms of carbon emissions and sulfur emissions. Carbon emissions in 2100 are $6 \mathrm{GtC}$ lower in the $\mathrm{B} 2$ scenario. Sulfur emissions are $100 \mathrm{MtS}$ lower. However, the reduced warming effect of lower carbon emissions in the B2 scenario is essentially offset by the reduced cooling effect due to lower sulfur emissions. Thus the projected increases in radiative forcing for the B2 and IS92a scenarios are quite similar in 2100. In this, the B2 storyline's environmental emphasis has a seemingly perverse effect. Because the environmental emphasis is regional and national rather than global, and because both the impacts and potential remedies of sulfur pollution are more immediate and local than those of potential global warming, sulfur reductions are a focus of attention. The result is sulfur reductions that act to exacerbate global warming, other things being equal.

The B2S550 scenario adds a carbon constraint (stabilization by 2100 at $550 \mathrm{ppmv}$ ) to the B2 scenario. Carbon emissions in the B2S550 scenario peak in 2040 at $10.7 \mathrm{GtC}$, before dropping to $5.5 \mathrm{GtC}$ by 2100 . Roughly $40 \%$ of the $8.7 \mathrm{GtC}$ difference in 2100 between the B2 scenario and the B2S550 scenario is due to fuel switching, primarily away from coal. $32 \%$ is from carbon scrubbing, $14 \%$ is due to price-induced energy demand reductions, and $12 \%$ is from hydrogen injection into the natural gas system. The B2S550 scenario's radiative forcing in 2100 is $8 \%$ lower than that of the B2 scenario, and its best guess temperature change is $0.2^{\circ} \mathrm{C}$ lower. The GWP loss due to higher energy prices is about $1.7 \%$ of the B2 scenario's GWP in 2100.

We believe these results offer two main messages to policy-makers contemplating their options assuming a future that most closely approximates the B2 storyline. First, although the inclusion of technological change (in comparison with the IS92a scenario) and updated resource estimates may lead to lower carbon emissions, they are also likely to lead to lower sulfur emissions. And that means no significant change, at the average global level, in terms of projected radiative forcing.

Second, this quantification indicates that there are plausible technological trajectories that could stabilize the carbon concentration at $550 \mathrm{ppmv}$, if that were chosen as a worthwhile target. These come at a cost, $1.7 \%$ of GWP, but it is not large compared to projected GWP growth (almost a factor of 12 by 2100 ). Two caveats are in order, however. First, the existence of such technological trajectories says nothing about the policies that would be required to implement them, e.g., taxes, subsidies, research and development. performance standards, technological mandates, emission permits, energy labeling. green certificates, technology transfer, and so on. These are well outside the scope of this paper. Second is the fact that other quantifications of the B2 scenario may suggest other technological trajectories for a similar stabilization target. In this case, we hope others will offer alternative quantifications of the B2 scenario so that robust strategies for stabilization in a B2 world can be identified.

We gratefully acknowledge Alan McDonald for his scientific advice and editorial5work which significantly improved the quality of this article. With his expertise, assistance, and motivation we were able to finalize the paper under tight time constraint. 


\section{References}

1. Morita, T., and Lee, H.-C.: IPCC SRES Database, Version 0.1, Emission Scenario Database Prepared for IPCC Special Report on Emission Scenarios, Mitigation and Adaptation Strategies for Global Change 3(2-4), 121-131 (1998).

2. Pepper, W., Leggett. J., Swart, R., Wasson, J., Edmonds, J., and Mintzer, I.: Emission Scenarios for the IPCC-An Update: Assumptions, Methodology, and Results. Prepared for the Intergovernmental Panel on Climate Change, Working Group 1, May 1992.

3. IPCC (Intergovernmental Panel on Climate Change): Climate Change 1994, Radiative Forcing of Climate Change and on Evaluation of the IPCC IS92 Emission Scenarios. Cambridge University Press, UK, 1995.

4. Nakićenović, N., Grübler, A., and McDonald. A.: Global Energy Perspectives, Cambridge University Press, Cambridge, UK, 1998.

5. Jiang, K., Masui, T., Morita, T., and Matsuoka, Y.: Long-Term GHG Emission Scenarios for Asia-Pacific and the World, Technological Forecasting and Social Change 63(2-3) 207-229 (2000).

6. Sankovski. A.. Barbour. W., and Pepper. W.: Quantification of the IS 99 Emission Scenario Storylines Using the Atmospheric Stabilization Framework. Technological Forecasting and Social Change 63(2-3) 263-287 (2000).

7. de Vries, B., Bollen. J., Bouwman. L., den Elzen, M.. Janssen, M., and Kreileman, E.: Greenhouse Gas Emissions in an Equity-. Environment- and Service-Oriented World: An IMAGE-Based Scenario for the 21st Century, Technological Forecasting and Social Change 63(2-3) 137-174 (2000).

8. Grübler, A.: Technology and Global Change. Cambridge University Press. Cambridge. UK. 1998.

9. Nakićenović. N.: Freeing Energy from Carbon. Daedalus, Journal of the American Academy of Arts and Sciences 125(3), 95-112 (1996).

10. Wigley, T. M. L., and Raper, S. C. B.: Model for the Assessment of Greenhouse-Gas Induced Climate Change (MAGICC Version 2.3). The Climate Research Unit. University of East Anglia. UK, 1997.

11. Watson. R.. Zinyowera. M. C., and Moss. R., eds.: Climate Change 1995. Impacts, Adaptations and Mitigation of Climate Change: Scientific Analyses. Contribution of Working Group II to the Second Assessment Report of the Intergovernmental Panel on Climate Change. Cambridge University Press. Cambridge, UK. 1996.

12. UN (United Nations): World Population Projections to 2150. United Nations Department of Economic and Social Affairs Population Division. New York, NY, USA, 1998.

13. Lutz, W., ed.: The Future Population of the World: What Can We Assume Today? (Revised and updated edition), Earthscan, London, UK, 1996.

14. Maddison, A.: Monitoring the World Economy 1820-1992. OECD Development Center Studies, Organization for Economic Co-operation and Development, Paris, France.

15. Wigley, T. M. L., and Raper, S. C. B.: Implications for climate and sea level of revised IPCC emissions scenarios, Nature 357, 293-300 (1992).

16. Wigley, T. M. L.: Balancing the carbon budget: Implications for projections of future carbon dioxide concentration change, Tellus 45B, 409-425 (1993).

17. Nakićenović, N., Amann, M., and Fischer, G.: Global Energy Supply and Demand and Their Environmental Effects. Report to the Central Research Institute of the Electric Power Industry, International Institute for Applied Systems Analysis, Laxenburg. Austria, February 1998.

18. Messner, S., and Strubegger, M.: User's Guide for MESSAGE 111, WP-95-69. International Institute for Applied Systems Analysis, Laxenburg. Austria, 1995.

19. Messner, S., and Schrattenholzer, L.: MESSAGE-MACRO: Linking an Energy Supply Model with a Macroeconomic Module and Solving It Iteratively, Energy (in press).

20. Messner, S., and Strubegger, M.: User's Guide to CO2DB: The IIASA CO2 Technology Data Bank Version 1.0. Working Paper-91-31a, International Institute for Applied Systems Analysis, Laxenburg, Austria, 1991.

21. Strubegger, M., and Reitgruber, I.: Statistical Analysis of Investment Costs for Power Generation Technologies. Working Paper-95-109. International Institute for Applied Systems Analysis, Laxenburg, Austria, 1995.

22. Rogner, H.-H.: An Assessment of World Hydrocarbon Resources, Annual Review of Energy and the Environment 22, 217-262 (1997).

23. United Nations: United Nations Framework Convention on Climate Change (UNFCCC). UNFCCC Secretariat, Bonn, Germany, 1992.

24. Nakićenović, N., Grübler, A., Ishitani, H., Johansson, T., Marland. G., Moreira, J. R., and Rogner, H.-H.: Energy primer, in Climate Change 1995: Impacts, Adaptations and Mitigation of Climate Change: ScientificTechnical Analysis. Contribution of Working Group II to the Second Assessment Report of the IPCC; Cambridge University Press, Cambridge, UK, 1996, pp. 75-92.

25. Olivier, J. G. J., Bouwman, A. F., van der Maas, C. W. M., Berdowski, J. J. M., Veldt, C., Bloos, J. P. J., Visschedijk, A. J. H., Zanfield, P. Y. J., and Haverlag, J. L.: Description of EDGAR Version 2.0: A Set of 
Global Emission Inventories of Greenhouse Gas Gases and Ozone-Depleting Substances for All Anthropogenic and Most Natural Sources on a per Country Basis and on a $1^{\circ} \times 1^{\circ}$ grid. RIVM Report 771060002 , RIVM, Bilthoven, the Netherlands, 1996.

26. Morita, T., Matsuoka, Y., Kanuma, M.. Harasawa. H., and Kai. K.: AIM-Asian-Pacific Integrated Model for Evaluating Policy Options to Reduce GHG Emissions and Global Warming Impacts. Paper for Workshop on Global Warming Issues in Asia, 8-10 September 1997.

27. Schönhart. W.: Assessment of Future Energy Technology Characteristics. Diplomarbeit, Technical University, Graz, Austria. 1999.

28. Grübler. A.: A Review of Global and Regional Sulfur Emission Scenarios. Mitigation and Adaptation Strategies for Global Change 3(2-4), 383-418 (1998).

29. Wigley, T. R.. Richels, R., and Edmonds, J.: Economic and Environmental Choices in the Stabilization of Atmospheric CO2 Concentrations, Nature 359(6562), 240-243 (1996).

30. Akimoto, K.: A Simple Climate Change Model. Manuscript. International Institute for Applied Systems Analysis, Laxenburg, Austria. 1997.

31. Edmonds. J., and Richels, R.: The economics of stabilizing atmospheric $\mathrm{CO}$, concentrations. Energy Policy 23(4/5). 370-373 (1995).

32. Schrattenholzer. L.: EMF14: Integrated Assessment of Climate Change Models, First Round Scenario Results. International Institute for Applied Systems Analysis, Laxenburg, Austria.

33. Marchetti, C.: How to Solve the CO2 Problem without Tears. International Journal of Hydrogen Energy 14(8), 493-506 (1989).

34. Nakićenović, N.: Technological Substitution and Long Waves in the USA, The Long-Wave Debate. Tibor Vasko, ed., Springer-Verlag. Berlin, 1987. 
